\title{
Sympathetic Nervous System Activation and Its Modulation: Role in Atrial Fibrillation
}

\author{
Revathy Carnagarin ${ }^{1}$, Marcio G. Kiuchi', Jan K. Ho ${ }^{1}$, Vance B. Matthews ${ }^{1}$ and \\ Markus P. Schlaich ${ }^{1,2,3 *}$ \\ 1 Dobney Hypertension Centre, School of Medicine, Royal Perth Hospital Unit, Medical Research Foundation, The University \\ of Western Australia, Perth, WA, Australia, ${ }^{2}$ Departments of Cardiology and Nephrology, Royal Perth Hospital, Perth, WA, \\ Australia, ${ }^{3}$ Neurovascular Hypertension and Kidney Disease Laboratory, Baker Heart and Diabetes Institute, Melbourne, VIC, \\ Australia
}

\section{OPEN ACCESS}

Edited by: Alberto Porta,

University of Milan, Italy

Reviewed by: Michela Masè,

University of Trento, Italy Raffaello Furlan,

Humanitas Research Hospital, Italy

*Correspondence:

Markus P. Schlaich

markus.schlaich@uwa.edu.au

Specialty section

This article was submitted to

Autonomic Neuroscience,

a section of the journal

Frontiers in Neuroscience

Received: 03 September 2018

Accepted: 31 December 2018

Published: 23 January 2019

Citation:

Carnagarin R, Kiuchi MG, Ho JK Matthews VB and Schlaich MP (2019)

Sympathetic Nervous System Activation and Its Modulation: Role

in Atrial Fibrillation.

Front. Neurosci. 12:1058. doi: 10.3389/fnins.2018.01058
The autonomic nervous system (ANS) has a significant influence on the structural integrity and electrical conductivity of the atria. Aberrant activation of the sympathetic nervous system can induce heterogeneous changes with arrhythmogenic potential which can result in atrial tachycardia, atrial tachyarrhythmias and atrial fibrillation (AF). Methods to modulate autonomic activity primarily through reduction of sympathetic outflow reduce the incidence of spontaneous or induced atrial arrhythmias in animal models and humans, suggestive of the potential application of such strategies in the management of AF. In this review we focus on the relationship between the ANS, sympathetic overdrive and the pathophysiology of $A F$, and the potential of sympathetic neuromodulation in the management of AF. We conclude that sympathetic activity plays an important role in the initiation and maintenance of $A F$, and modulating ANS function is an important therapeutic approach to improve the management of $\mathrm{AF}$ in selected categories of patients. Potential therapeutic applications include pharmacological inhibition with central and peripheral sympatholytic agents and various device based approaches. While the role of the sympathetic nervous system has long been recognized, new developments in science and technology in this field promise exciting prospects for the future.

Keywords: autonomic nervous system, hypertension, neuromodulation, atrial fibrillation, sympathetic overdrive

\section{CARDIAC AUTONOMIC NERVOUS SYSTEM (ANS) ANATOMY}

The heart is extensively innervated and effectively regulated by the autonomic nervous system (ANS) through its sympathetic and parasympathetic branches (Kimura et al., 2012). The cardiac neural control occurs at multiple levels with each level capable of parallel processing of afferent neurotransmission and efferent cardiac sympathetic outflow (Esler, 2004). The ganglion cells of the ANS are located either inside (intrinsic) or outside the heart (extrinsic) and play an important role in cardiac function and arrhythmogenesis. The human cardiac intrinsic nervous system is made of ganglionated plexi (GP), which contain local circuit neurons of many types and chemo- and mechanosensory neurons that are distributed across the heart (Schotten et al., 2011). The GP are typically well innervated with both adrenergic and vagal nerve terminals and are accommodated 
in the fat pads, which are located mainly around the pulmonary vein ostia. The extrinsic sympathetic innervation is mediated via the cervical, stellate (cervicothoracic), and thoracic ganglia. Parasympathetic extrinsic innervation is transmitted via the vagus nerve, although sympathetic fibers are located in vagal nerves and parasympathetic fibers in sympathetic nerves as well (Kawashima, 2005; Seki et al., 2014).

The extrinsic nerves run through the hilum of the heart along the great cardiac vessels and divide into seven epicardial subplexi, the intrinsic neural pathways of the ANS (Pauza et al., 2000). Small nerve fibers create a vast neural complex of small interconnecting efferent and afferent sympathetic, parasympathetic, and mixed nerve fibers, that contain the neurotransmitters, such as noradrenaline and acetylcholine, respectively, but some also include neuropeptide $\mathrm{Y}$, somatostatin, vasoactive intestinal polypeptide, and substance P (Marron et al., 1994, 1995; Armour et al., 1997; Esler et al., 2006a; Tan et al., 2006; Deneke et al., 2011). The density of small fibers and ganglia is most significant in the posterior zone of the left atrium and surrounding the antrum of the left pulmonary veins (PVs) (Chevalier et al., 2005; Tan et al., 2006). The atria are mostly parasympathetically innervated, whereas the ventricles are primarily innervated by sympathetic nerve fibers (where only $16 \%$ of total cardiac ganglia reside) (Pauza et al., 2000; Kawano et al., 2003; Petraitiene et al., 2014). GP are clusters of ganglia from different subplexi and function as an intersection point of parasympathetic and sympathetic nerves and interconnect the intrinsic ANS (Armour et al., 1997; Hou et al., 2007; MalcolmeLawes et al., 2013). The atrial GP are placed adjacent to the sinus node and PVs and are present in epicardial fat pads (Figure 1). Ventricular GP are located near the interventricular groove (Armour et al., 1997). The ligament of Marshall, the embryonic remnant of the left superior caval vein, close to the left superior PV is extensively innervated with parasympathetic and sympathetic nerves (Kim et al., 2000; Ulphani et al., 2007).

\section{PATHOPHYSIOLOGY OF ATRIAL FIBRILLATION}

Autonomic nervous system activation has been well-known as a central determining factor of atrial arrhythmogenesis, (Sharifov et al., 2004; Chen and Tan, 2007; Shen et al., 2011; Shen and Zipes, 2014). Studies involving modulation of the sympathetic limb of ANS demonstrated that suppression of sympathetic tone leads to a notable reduction in atrial vulnerability to AF induction and post-ablation AF recurrence (Linz et al., 2012; Pokushalov et al., 2012). The prevalence of AF increases with age, affecting around $0.5 \%$ of the general population under 40 years of age, $>5 \%$ of the general population over 65 years of age, and $>10 \%$ of the general population over 80 years of age (Sankaranarayanan et al., 2013). In young patients, there was a shift toward vagal dominance in lone AF and nocturnal paroxysmal AF predominantly (Jayachandran et al., 2000). In patients with paroxysmal AF and syncope, there is an abnormal neural response even during sinus rhythm, at which AF triggers vasovagal syncope (Brignole et al., 1993). It is also important to highlight that AF in younger patients is associated with higher mortality rate than matched controls. Patients admitted into the hospital with incidental AF had a worse prognosis when compared to patients without AF, with higher risk of all-cause mortality in the younger age group when compared to the over75-year-old population (Andersson et al., 2013).

Atrial fibrillation promotes shortening of the atrial refractory period and AF cycle length during the first days of the arrhythmia, mostly due to downregulation of the $\mathrm{Ca}^{2+}$-inward current and upregulation of inward rectifier $\mathrm{K}^{+}$currents (Van Wagoner et al., 1999; Dobrev et al., 2005). Conversely, the structural cardiac disease leads to an extension of the atrial refractory period, demonstrating the heterogeneity of mechanisms causing AF in different patients (Schotten et al., 2011). Hyper-phosphorylation of various $\mathrm{Ca}^{2+}$-handling proteins may contribute to increasing spontaneous $\mathrm{Ca}^{2+}$ release events and eliciting activity (Voigt et al., 2012, 2014), thus provoking atrial ectopic beats, and thereby AF. Interestingly, the instability theory of $\mathrm{Ca}^{2+}$-handling has been recently challenged (Christ et al., 2014; Greiser et al., 2014), raising the hypothesis that $\mathrm{Ca}^{2+}$-induced calcium release may mediate AF in structurally remodeled atria, demonstrating how a modified autonomic tone can cause AF (Nguyen et al., 2009).

\section{Focal Initiation and Maintenance of AF}

Haissaguerre et al. (2014) reported that a focal source in the pulmonary veins could initiate AF, and ablation of this source could eliminate recurring AF (Haissaguerre et al., 1998). The mechanisms of focal activity perhaps cover both triggered activity and local re-entry (Atienza et al., 2006; Patterson et al., 2007). Hierarchical organization of AF with rapidly activated zones promoting the arrhythmia has been demonstrated in individuals with paroxysmal AF (Mandapati et al., 2000; Sahadevan et al., 2004). However, it seems that the organization of these rapidly activated zones are less well demarcated in patients with persistent AF (Sanders et al., 2006).

\section{The Multiple Wavelet Hypothesis and Rotors as Sources of AF}

The multiple wavelets and organized sources theories, though unclear are the two principal proposed paradigms of AF perpetuation. Moe et al. (1964) proposed, through a mathematical model, that multiple wavelets randomly propagating through the atria are capable of perpetuating AF which in turn provoke wave breaks, and generates new daughter wavelets. Though AF would be sustained as long as the number of wavelets is beyond a critical level, it is still unknown whether these wavelets are driving AF or if they are simply passive, and result from the breakup of more organized waves. Whilst the multiple wavelet concept is supported by theoretical rationale (Moe and Abildskov, 1959), experimental and clinical data (Cox et al., 1991), optical mapping techniques identified that wavelets resulting from the breakup of high frequency organized waves were not capable of maintaining AF independently (Chen et al., 2000). In patients with longstanding AF, the fibrillatory waves are due to epicardial breakthrough of waves that propagate in the deep layers of the atrial wall providing a constant independent 


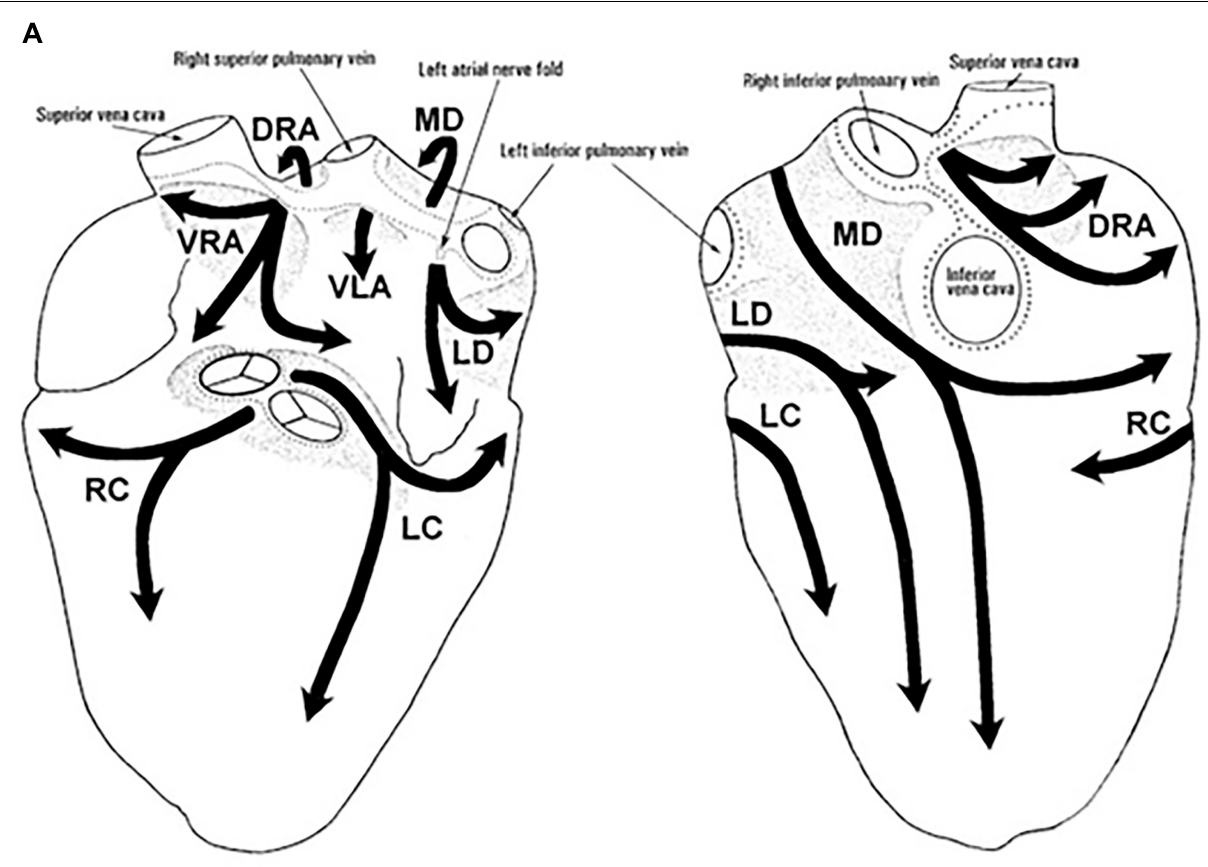

B

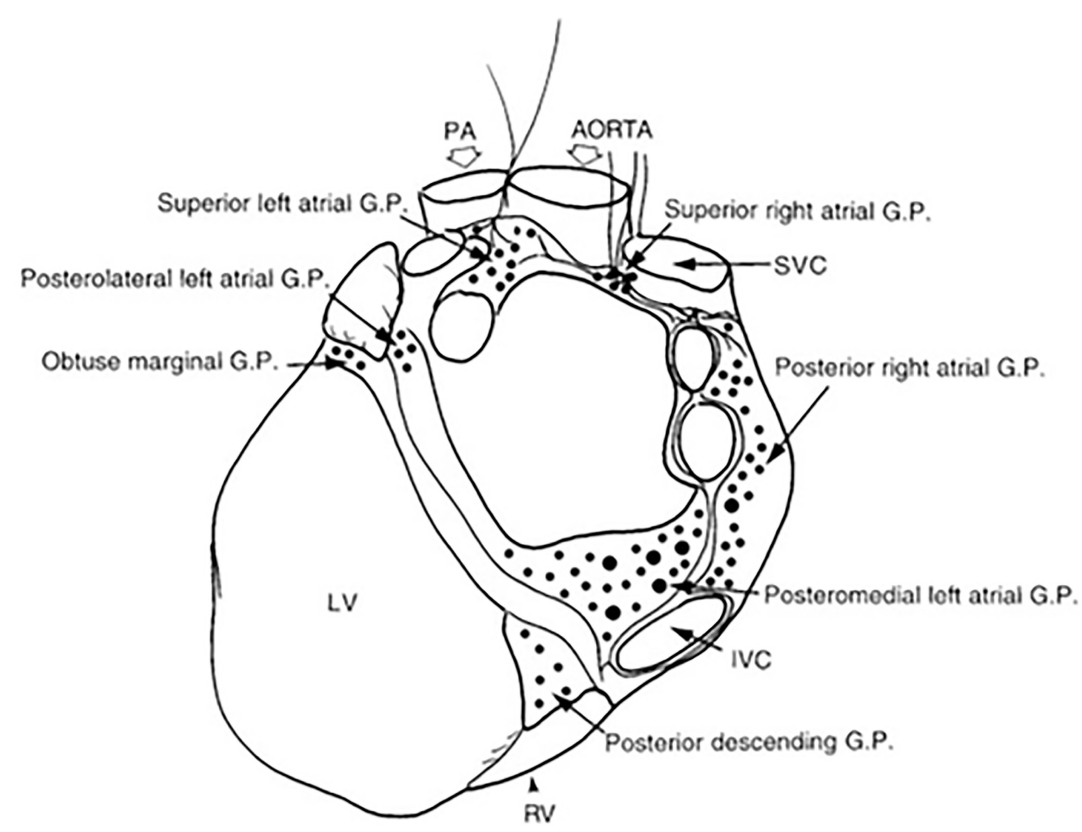

FIGURE 1 | Anatomy of the intrinsic autonomic nervous system. The extensive network of epicardial nerves on the atria and ventricles are divided in 7 subplexi: (A) Left is a posterior and right is an anterior view of the heart. Along these subplexi, ganglia are localized, conglomerated in ganglion plexi (GP) marked in light gray (Pauza et al., 2000). (B) The major atrial and ventricular GP from a posterior view of the heart (Armour et al., 1997). DRA, dorsal right atrial ganglionated subplexus; IVC, inferior vena cava; LC, left coronary ganglionated subplexus; LD, left dorsal ganglionated subplexus; LV, left ventricle; MD, middle dorsal ganglionated subplexus; PA, pulmonary artery; RC, right coronary ganglionated subplexus; RV, right ventricle; SVC, superior vena cava; VLA, ventral left atrial ganglionated subplexus; VRA, ventral right atrial ganglionated subplexus.

source originating over the entire epicardial surface (Allessie et al., 2010; de Groot et al., 2010). Early ablative termination of AF in the PV may not completely abolish the presence of PV antrum wavelets over time, which can in turn cause AF (Haissaguerre et al., 2005; Calkins et al., 2012) resulting in limited clinical impact (Beukema et al., 2008).
Studies showed the presence of high-frequency spiral wave-like activity emanating regularly from the left atrium, subsequently driving irregular fibrillatory conduction in the rest of the atria (Schuessler et al., 1992; Mandapati et al., 2000; Verheule et al., 2010) whilst complex signal morphologies were associated with areas of slow conduction, wave collision, 
fibrillatory conduction, turning into wavelet pivot points and rotor meandering, or autonomic activation (Lu et al., 2008; Vaquero et al., 2008; Zlochiver et al., 2008). Localized source premise is based on experimental models in which organized re-entrant circuits, called "rotors" (Skanes et al., 1998; Vaquero et al., 2008) or focal impulses (Sahadevan et al., 2004) disorganize into AF. Jalife and co-workers clearly demonstrated that pacinginduced AF was due to the presence of a very rapid rotor (15$20 \mathrm{~Hz}$ ) in the left atrium (Jalife et al., 2002). The CONFIRM trial demonstrated for the first time that localized sources in the form of electrical rotors and focal impulses are capable of sustaining AF in humans (Narayan et al., 2012). Furthermore, they also proved that brief ablation (Focal Impulse and Rotor Modulation, FIRM) of patient-specific AF-sustaining sources was able to terminate or consistently reduce persistent or paroxysmal AF prior to any conventional ablation in $86 \%$ of patients, and substantially increase long-term AF elimination compared to traditional AF ablation alone (Narayan et al., 2012). However, the results of the CONFIRM trial were limited to small series of patients with mixed AF types, so the actual role of stable rotors in more persistent forms remains to be proven. Further, in the absence of convincing evidence that human AF is driven by a single rotor, it is puzzling how we should interpret the CONFIRM study. In itself, this observation does not prove that human $\mathrm{AF}$ is driven by a single rapid source and the reported clinical success needs to be confirmed by other centers, especially in patients with longstanding persistent AF (Allessie and de Groot, 2014). Moreover, these studies utilize a low-resolution mapping system, which is not completely satisfactory in delivering mechanistic insights to draw conclusions (Ravelli and Mase, 2014). However, the high success rate of AF termination by targeting identified local sources strongly supports the hypothesis of rapidly organizing sources as key for the maintenance of AF.

\section{CLINICAL CONDITIONS THAT MAY ACT AS PREDISPOSING FACTORS TO AF}

Multiple cardiovascular diseases and associated conditions increase the risk of developing AF (Table 1), recurrent AF, and AF-related consequences. Diagnosing such conditions, as well as preventing and treating them are vital to prevent AF and its disease burden. Knowledge of these factors and their management is therefore important for optimal treatment of AF patients (Abed et al., 2013; Pathak et al., 2014). The ANS exerts significant control on both cardiac electrophysiology as well as conditions such as, hypertension which is often associated with exaggerated sympathetic tone and is the single most important clinical factor that accounts for around $80 \%$ of AF (Schotten et al., 2011). This is further complicated by the associated atrial remodeling and dilatation that increases the probability of repetitive firing or even the presence of episodic re-entrant activation circuits. Other clinical conditions commonly associated with AF include cardiomyopathy, valvular and coronary heart disease, heart failure, metabolic syndrome and diabetes, suggested to contribute to around $20-30 \%$ of AF cases (Psaty et al., 1997; Schoonderwoerd et al., 2008;
TABLE 1 | Cardiovascular and other conditions independently associated with atrial fibrillation.

\begin{tabular}{|c|c|}
\hline Characteristic/comorbidity & Association with AF \\
\hline $\begin{array}{l}\text { Genetic predisposition (based on multiple } \\
\text { common gene variants associated with AF) }\end{array}$ & $\mathrm{HR}$ range $0.4-3.2$ \\
\hline Older age & HR: \\
\hline 50-59 years & 1.00 (reference) \\
\hline 60-69 years & 4.98 (95\% Cl 3.49-7.10) \\
\hline 70-79 years & 7.35 (95\% Cl 5.28-10.2) \\
\hline 80-89 years & 9.33 (95\% Cl 6.68-13.0) \\
\hline Hypertension (treated) vs. none & HR 1.32 (95\% Cl 1.08-1.60) \\
\hline Heart failure vs. none & HR 1.43 (95\% Cl 0.85-2.40) \\
\hline Valvular heart disease vs. none & RR 2.42 (95\% Cl 1.62-3.60) \\
\hline Myocardial infarction vs. none & HR 1.46 (95\% Cl 1.07-1.98) \\
\hline Thyroid dysfunction & (reference: euthyroid) \\
\hline Hypothyroidism & HR $1.23(95 \%$ Cl 0.77-1.97) \\
\hline Subclinical hyperthyroidism & RR 1.31 (95\% Cl 1.19-1.44) \\
\hline Overt hyperthyroidism & RR 1.42 (95\% Cl 1.22-1.63) \\
\hline Obesity & HR: \\
\hline None $\left(\mathrm{BMl}<25 \mathrm{~kg} / \mathrm{m}^{2}\right)$ & 1.00 (reference) \\
\hline Overweight (BMl 25-30 kg/m²) & $1.13(95 \%$ Cl 0.87-1.46) \\
\hline Obese $\left(\mathrm{BMI} \geq 31 \mathrm{~kg} / \mathrm{m}^{2}\right)$ & 1.37 (95\% Cl 1.05-1.78) \\
\hline Diabetes mellitus vs. none & HR 1.25 (95\% Cl 0.98-1.60) \\
\hline Chronic obstructive pulmonary disease & $\mathrm{RR}:$ \\
\hline FEV $1 \geq 80 \%$ & 1.00 (reference) \\
\hline FEV1 60-80\% & 1.28 (95\% Cl 0.79-2.06) \\
\hline FEV1 $<60 \%$ & $2.53(95 \%$ Cl 1.45-4.42) \\
\hline Obstructive sleep apnoea vs. none & HR 2.18 (95\% Cl 1.34-3.54) \\
\hline Chronic kidney disease & OR: \\
\hline None & 1.00 (reference) \\
\hline Stage 1 or 2 & 2.67 (95\% Cl 2.04-3.48) \\
\hline Stage 3 & 1.68 (95\% Cl 1.26-2.24) \\
\hline Stage 4 or 5 & $3.52(95 \%$ Cl 1.73-7.15) \\
\hline Smoking & HR: \\
\hline Never & 1.00 (reference) \\
\hline Former & $1.32(95 \% \mathrm{Cl} 1.10-1.57)$ \\
\hline Current & $2.05(95 \% \mathrm{Cl} 1.71-2.47)$ \\
\hline Alcohol consumption & RR: \\
\hline None & 1.00 (reference) \\
\hline $1-6$ drinks/week & 1.01 (95\% Cl 0.94-1.09) \\
\hline 7-14 drinks/week & 1.07 (95\% Cl 0.98-1.17) \\
\hline 15-21 drinks/week & $1.14(95 \%$ Cl 1.01-1.28) \\
\hline >21 drinks/week & 1.39 (95\% Cl 1.22-1.58) \\
\hline Habitual vigorous exercise & RR: \\
\hline Non-exercisers & 1.00 (reference) \\
\hline$<1$ day/week & 0.90 (95\% Cl 0.68-1.20) \\
\hline 1-2 days/week & 1.09 (95\% Cl 0.95-1.26) \\
\hline 3-4 days/week & 1.04 (95\% Cl 0.91-1.19) \\
\hline 5-7 days/week & $1.20(95 \% \mathrm{Cl} 1.02-1.41)$ \\
\hline
\end{tabular}

AF, atrial fibrillation; BMI, body mass index; Cl, confidence interval; FEV1, forced expiratory volume in $1 \mathrm{~s}$; $H R$, hazard ratio; $O R$, odds ratio; $R R$, risk ratio. Adapted from Kirchhof et al. (2016).

Mahfoud et al., 2011; Schotten et al., 2011; Selmer et al., 2012; Schnabel et al., 2015; Vermond et al., 2015). These clinical pathologies induce electrical, structural and autonomic atrial 
remodeling which results in conduction abnormalities such as rapidly firing focus and multiple complex (Buch et al., 2003; Gami et al., 2007; Aizer et al., 2009; Chamberlain et al., 2011; Kim et al., 2014; Larsson et al., 2014) re-entrant circuits, thereby AF (Figure 2). In addition, increased renin-angiotensin-aldosterone system activity associated with sympathetic overdrive induced profibrotic cardiac signaling, atrial fibrosis and fibrillation (Kumagai et al., 2003; Ehrlich et al., 2006; Baber et al., 2011; Reil et al., 2012).

Autonomic remodeling may modify the reaction to ANS stimulation and the balance between the parasympathetic and sympathetic innervation (Coumel, 1996; Patterson et al., 2005; Furukawa et al., 2009; Ng et al., 2011; Shen et al., 2011). Increased sympathetic nerve density has been described in patients with permanent AF, but whether this is compensatory to increased vagal stimulation or causative of AF is unknown (Gould et al., 2006; Deneke et al., 2011). A heterogeneous increase in sympathetic innervation in the atria of dogs on rapid atrial pacing for long periods increases AF susceptibility (Jayachandran et al., 2000). Increased sympathetic and vagal nerve discharges before the onset of atrial arrhythmias in dogs with pacinginduced congestive heart failure by direct nerve recordings from the stellate ganglia and vagal nerves was also reported (Ogawa et al., 2007). Undeniably, atrial tachyarrhythmias in dogs presenting with congestive heart failure by fast cardiac pacing were prevented by prophylactic ablation of the stellate ganglion and the T2 to T4 thoracic sympathetic ganglia (Ogawa et al., 2007). In the same animal model of heart failure, $\mathrm{Ng}$ et al., also demonstrated increased sympathetic and parasympathetic nerve growth mostly in the pulmonary veins and the posterior wall of the left atrium (Ng et al., 2011).

In humans, PV ectopy, often originating from superior PVs, normally triggers paroxysmal AF (Haissaguerre et al., 1998). Animal and human studies have shown that stimulation of the GP close to PV triggers PV ectopies (Scherlag et al., 2005; Lim et al., 2011). In canine PVs, parasympathetic activation decreased action potential duration, while sympathetic activation increased myocardial cytoplasmatic $\left(\mathrm{Ca}^{2+}\right)$ (Patterson et al., 2005). Both components were necessary for early afterdepolarizations in PVs, consequently triggering AF. Ectopic activity in other highly innervated structures (ligament of Marshall) possibly also triggers AF (Chevalier et al., 2005; Scherlag et al., 2005; Tan et al., 2006). During catheter ablation procedures stimulation of the ligament of Marshall caused ectopic beats and triggered AF

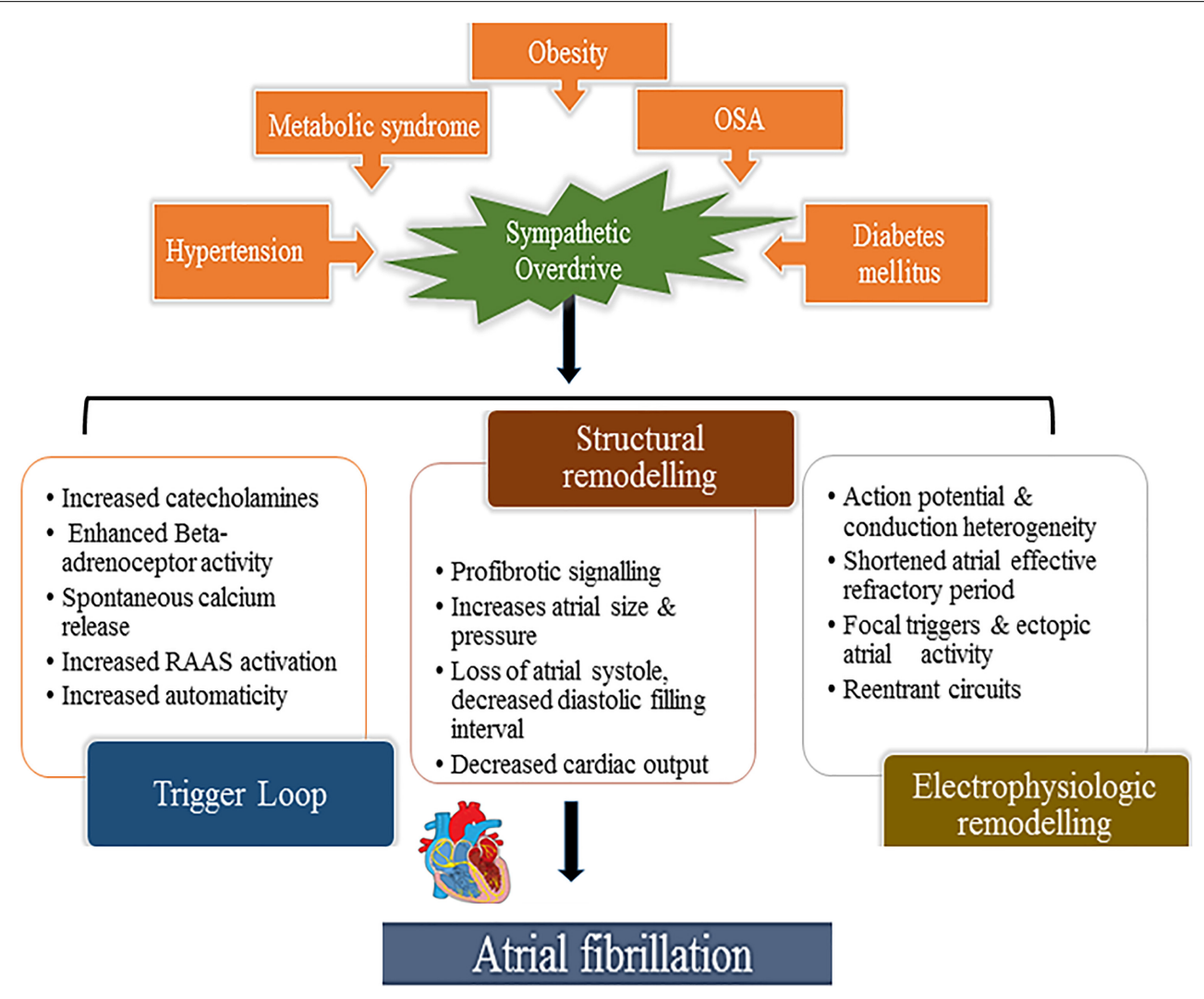

FIGURE 2 | Aberrant sympathetic activation in conditions such as obesity (and particularly increased epicardial fat), hypertension, obstructive sleep apnea, diabetes mellitus and metabolic syndrome plays a fundamental role in the development of AF. Sympathetic activation through excess catecholamines in the circulation which increases calcium entry and the spontaneous release from the myocardial sarcoplasmic reticulum leading to enhanced automaticity (trigger loop) and enhanced renin-angiotensin-aldosterone provokes pro-fibrotic signaling in the myocardium altering atrial size, pressure and consequent structural remodeling thereby inducing focal triggers and atrial ectopies. This occurs hand in hand with atrial electrical remodeling with shortened action potential duration, conduction disturbances, also facilitating re-entry circuits, promoting and sustaining AF. 
(Báez-Escudero et al., 2014). On the other hand, AF triggers are not restrained to densely innervated tissue alone. A study reported that in $\sim 30 \%$ of patients who required a repeat $\mathrm{PV}$ isolation ectopic firing from the left atrial appendage was detected (Di Biase et al., 2010).

Intense atrial fibrosis formation and cardiomyocyte hypertrophy are common features of structural remodeling. Atrial tissue fibrosis damages electrophysiological cell-to-cell coupling and conduction (Allessie et al., 2001; Nattel, 2002; Iwasaki et al., 2011; Schotten et al., 2011; Wakili et al., 2011). Long-term AF induces myocyte hypertrophy and increases endomysial fibrosis. This is accompanied by dissociated conduction and electrical dissociation between the epicardial layer and the endocardial bundle connections frequently promoting permanent forms of AF (Eckstein et al., 2011; Schotten et al., 2011). Conditions other than AF can also lead to atrial structural remodeling including chronic arterial hypertension which has been shown to cause electro-structural changes characterized by conduction abnormalities, atrial inflammation and fibrosis thereby increasing the risk of $\mathrm{AF}$ induction (Lau et al., 2010). Congestive heart failure induces structural remodeling characterized by increased fibrosis and changes in gap junctions, provoking conduction heterogeneity which promotes formation of micro-re-entry and macro-re-entry circuit pathways ( $\mathrm{Li}$ et al., 1999). Long-term obstructive sleep apnoea is linked to significant atrial remodeling characterized by atrial enlargement, site-specific and extensive conduction abnormalities, as well as delayed sinus node recovery time in humans (Witkowski et al., 2011; Dimitri et al., 2012). The described alterations may have a crucial role in the generation of AF substrates.

Sympathetic activation also plays a major role in atrial arrhythmias following cardiac surgeries and post-operative (postop) AF is associated with reduced long term survival with cardiac surgeries such as the coronary bypass and valvular surgeries especially the aortic valve replacement (Girerd et al., 2011). Often finding suggestive of enhanced sympathetic activation such as elevated nor-epinephrine levels (Kalman et al., 1995), increased sinus rate, atrial ectopy and time- and frequencydomain parameters of heart rate variability are associated with the onset of AF following cardiac surgeries (Dimmer et al., 1998; Amar et al., 2003). Ventral cardiac denervation significantly reduced the incidence and severity of $\mathrm{AF}$ in patients undergoing low-risk coronary bypass surgery (Melo et al., 2004). Postoperative AF is also common in patients who have undergone lung transplantation rather than cardiac transplantation, an effect attenuated by cardiac autonomic denervation that occurs in heart transplant patients (Dizon et al., 2009). Moreover, in a large series of patients following orthotopic cardiac transplant, macro re-entrant tachycardias (flutter and scar re-entry) seem to be the most common supraventricular arrhythmias in stable patients which are often supressed by catheter ablation. The blockade of $\beta$-receptors in patients presenting with acute postoperative AF has been effective in preventing recurrence of this arrhythmia after successful cardioversion (Kühlkamp et al., 2000; Nergårdh et al., 2007). Though post-op AF is of multifactorial etiology, sympathetic activation appears to be the most relevant predisposing mechanism of post-op AF and in line with this, the 2010 European Society of Cardiology guidelines recommend $\beta$-blocker treatment as first-line therapy in preventing post-op AF following cardiac surgeries (Camm et al., 2010).

\section{SYMPATHOLYTIC THERAPY - A POSSIBLE STRATEGY IN THE MANAGEMENT OF AF?}

\section{Pharmacological Sympathetic Inhibition}

Given the contribution of sympathetic overdrive in the development of AF, sympathetic inhibition represents a logical therapeutic approach in the management of AF and the frequently coexisting hypertension, thereby alleviating the associated cardiovascular mortality and morbidity. Autonomic dysfunction characterized by sympathetic overdrive in scenarios of organic heart disease exhibits both electrical and structural remodeling of atrial myocardium in AF. Pharmacological sympatholysis can be achieved by using drugs such as clonidine and moxonidine. Clonidine is a centrally acting $\alpha 2$-adrenergic agonist that supresses the sympathetic outflow in the lower brainstem (Flacke et al., 1987), the preganglionic splanchnic nerve fibers and in postganglionic cardiac nerves fibers (Langer et al., 1980). In addition, clonidine prolongs atrioventricular node refractoriness by stimulation of parasympathetic outflow with beneficial effects on the control of ventricular response in patients with new-onset rapid AF (Roth et al., 1992). Moxonidine is an imidazoline I1-receptor agonist that inhibits sympathetic outflow at the level of the rostral ventrolateral medulla. In addition to effective blood pressure (BP) lowering and metabolic benefits (Haenni and Lithell, 1999; Chazova et al., 2006), moxonidine has been demonstrated to suppress atrial arrhythmogenesis (Lepran and Papp, 1994; Edwards et al., 2012; Cagnoni et al., 2016). In a subsequent study, moxonidine significantly increased the threshold dose of ouabain-induced cardiac arrhythmia by decreasing sympathetic tone (Mest et al., 1995). Moreover, moxonidine induced sympathetic inhibition decreased the AF burden in hypertensive patients with paroxysmal AF without any side effects (Deftereos et al., 2013). Furthermore, moxonidine reduced post-ablation recurrence of AF in hypertensive patients who underwent pulmonary vein isolation for drug-refractory paroxysmal AF (Giannopoulos et al., 2014).

Moxonidine seems specifically useful in obesity related hypertension where the sympathetic overdrive sustains both obesity and BP elevation. With the well-established relationship between abdominal obesity, the metabolic syndrome, and the development of AF, obese hypertensives are at a greater risk for AF. Studies have identified that autonomic dysfunction occurs early in the pathophysiology of AF and precedes the development of metabolic abnormalities such as insulin-resistance and obesity (Huggett et al., 2006; Julius and Jamerson, 1994; Palatini et al., 1999) which in turn maintain sympathetic activation via release of adipokines and other bioactive cytokines from visceral fat depots (Grassi et al., 1995; Alvarez et al., 2002; Huggett et al., 2004; Lambert et al., 2007, 2010). Alterations 
in norepinephrine transport and central sympathetic outflow have also been implicated in postural tachycardia syndrome (Lambert et al., 2008), anxiety and cardiovascular disease (Esler et al., 2006b), as well as panic disorder (Lambert et al., 2002). Furthermore, studies have shown that epi-/peri-cardial adipose tissue is an independent risk factor for AF (Al Chekakie et al., 2010) and adipocytes from the epicardial fat directly infiltrate into the myocardial wall resulting in enlargement of the ventricular myocardium and atrial septum thereby increasing the risk of AF (Iacobellis et al., 2003; Sarin et al., 2008; Mahabadi et al., 2009). Another highly relevant link in the current context is the noradrenaline-mediated increase in sodium glucose co-transporter- 2 (SGLT-2) expression (Matthews et al., 2017). This is important given that SGLT-2 inhibitors such as canagliflozin effectively reduce epicardial fat (Yagi et al., 2017) and empagliflozin improved glucose control and has been demonstrated to reduce cardiovascular events in T2DM (Zinman et al., 2015).

Sympathetic blockade at the periphery can also be achieved by beta-adrenergic blockers. Though beta-blockers are not generally regarded as membrane stabilizing agents, they delay atrial repolarization and protect against AF. It was speculated that beta-blockers suppress the pulmonary vein ectopy that triggers AF (Chen et al., 1999) as well as protect against adrenergically mediated shortening of the action potential duration (APD) which precipitates and maintains AF (Kühlkamp et al., 2000). Beta-blockers are a good first choice for the control of the ventricular response in AF and are widely used in the prevention of AF in patients following cardiothoracic surgery, in which AF occurs in approximately $30 \%$ of patients (Prystowsky et al., 1996).

\section{Device-Based Therapeutic Approaches for Sympathetic Inhibition}

Other interventions include device-based therapeutic approaches to modulate ANS to lower central sympathetic nerve activity such as renal denervation (RDN) and carotid body ablation. These approaches are primarily aimed at reducing sympathetic activity and $\mathrm{BP}$ in resistant hypertensive patients but are now investigated as potential treatment strategies in the context of AF.

\section{RENAL DENERVATION AND GANGLIONATED PLEXI ABLATION}

Recently, the AFFORD study, a single-arm pilot study including 20 patients with symptomatic paroxysmal or persistent AF, suggested that RDN alone was safe and able to decrease AF burden in $\mathrm{min}$ /day as measured using an implantable cardiac monitor (ICM) at 12-month follow-up accompanied by an improvement in quality of life (Feyz et al., 2018). A clinical study that assessed the antiarrhythmic effect of RDN in addition to pulmonary vein isolation (PVI) in HTN patients with symptomatic AF demonstrated that a mean $\mathrm{BP}$ reduction of 5-10 $\mathrm{mmHg}$ led to a 7\% decrease in AF burden as measured with an ICM (Romanov et al., 2017). Pokushalov et al. (2012) showed that RDN on top of PVI in patients with symptomatic $\mathrm{AF}$ and resistant $\mathrm{HTN}$ reduced the incidence of AF recurrence significantly. At 1 year $69 \%$ of the patients in the PVI + RDN group were free of AF episodes, while in the PVI only group, only $29 \%$ of the patients remained free of AF episodes (Pokushalov et al., 2012).

Mechanistic studies demonstrated that modulation of the SNS via RDN improved AF control (Hou et al., 2013). Linz et al. (2013a,b) demonstrated the effect of RDN on heart rate (RRinterval, $708 \pm 12 \mathrm{~ms}(\sim 85 \mathrm{bpm})$ vs. $577 \pm 19 \mathrm{~ms}(\sim 104 \mathrm{bpm})$, post- and pre-procedure respectively; $P=0.0021)$ and ventricular rate response in pigs with permanent AF. The authors described a reduction of $24 \%$ in ventricular rate response in the treated pigs vs. sham, as well shorter AF episodes post-RDN compared with sham (12 \pm 3 vs. $34 \pm 4$ s; $P=0.0091$ ) (Linz et al., 2013a,b). Effects of RDN on cardiac electrophysiology have already been extensively studied and found to be effective in animal models and humans (Okin et al., 2006; Symplicity HTN-2 Investigators et al., 2010; Brandt et al., 2012b). RDN predominantly impacts sympathetic tone and results in a reduction in heart rate and atrioventricular-conduction velocity in resistant hypertension population (Krum et al., 2009; Schlaich et al., 2010; Ukena et al., 2013). Recently, the SPYRAL HTN-OFF MED trial reported that the higher baseline heart rate was associated with higher BP decrease, which may indicate that RDN works better in patients with high sympathetic drive (assessed in the absence of interfering drugs) (Bohm et al., 2018).

In a prospective, longitudinal study of patients with controlled hypertension, paroxysmal AF and either normal renal function or chronic kidney disease (CKD), Kiuchi et al., applying an extensive ablation technique reported the incidence of AF recurrence. It was higher in CKD patients treated with PVI alone (61.5\%) than in CKD patients treated with PVI + RDN $(38.5 \%, P=0.0251)$ or non- CKD patients who underwent PVI (35.6\%, $P<0.0001)$ over $22.4 \pm 12.1$ months following intervention. In addition, they found an improvement in echocardiographic parameters such as indexed left atrial volume, left ventricular end-diastolic diameter, and left ventricular mass index in patients who underwent RDN compared to baseline and to other groups. Another important finding was that patients with CKD stage 4 who underwent only PVI (64.41\%) demonstrated a higher rate of AF recurrence than those subjected to PVI + RDN (33.33\%, $P=0.0409)$ (Kiuchi et al., 2017).

Chronic kidney disease and AF share risk factors and putative mechanisms suggesting that common pathophysiologic processes may drive both pathologies. One possible common link between $\mathrm{AF}$ and $\mathrm{CKD}$ is activation of the renin-angiotensin-aldosterone system (RAAS) (Goette et al., 2000; Tsai et al., 2004; Wachtell et al., 2005; Baber et al., 2011; Tsai et al., 2017). Angiotensin II can increase atrial pressure, promote atrial fibrosis, and modulate ion channels, all of which are involved in structural and electrical remodeling of the atria resulting in AF (Goette et al., 2000). In addition, gene polymorphisms in encoding components of this pathway have been linked to the development of AF (Tsai et al., 2004; Lubitz et al., 2014). Supporting these results are data demonstrating that $\mathrm{BP}$ reduction after $\mathrm{RDN}$ is associated with improvements in regional and global atrial conduction with reduction in ventricular mass and fibrosis (McLellan et al., 2015). Though the antiarrhythmic effects of RDN could be due 
to a synergistic effect of better BP control, withdrawing this important risk factor for AF recurrence, improves AF control by electrophysiological modification such as the prolongation of the atrial effective refractory period (Manolis et al., 2012; Wang et al., 2015).

Tsai et al. (2017) demonstrated that bilateral RDN, possibly via interrupting afferent renal innervation, led to substantial brain stem and bilateral stellate ganglion remodeling at 8 weeks' post-procedure in ambulatory canines (Tsai et al., 2017). These changes were associated with reduced ${ }^{18}$ FDG (fluorodeoxyglucose) - uptake in the brainstem, left stellate ganglion nerve activity and atrial tachyarrhythmic events. It was proposed that neural remodeling in the brain stem and stellate ganglion may partially explain the described antiarrhythmic effects of RDN (Tsai et al., 2017). Trans-synaptic degeneration is a phenomenon in the central and peripheral nervous system that may remain active both at the level of the insult and in remote brain structures for as long as 1 year following trauma (Bramlett and Dietrich, 2007) resulting in long-term functional consequences following RDN as shown in Figure 3. Meckler and Weaver (1984) showed that approximately $10 \%$ of bilateral renal sympathetic neurons in cats originated from the thoracic chain ganglia (stellate through T13). Because of the connections between these two structures, RDN may directly result in retrograde cell death of the stellate ganglion. Furthermore, the application of fluorescent dyes in the renal nerves results in fluorescent labeling of the sympathetic cell bodies in paravertebral and prevertebral ganglia (Ferguson et al., 1986; Gattone et al., 1986; Sripairojthikoon and Wyss, 1987).
Since the sympathetic preganglionic neurons that project to the stellate ganglion are dispersed in spinal cord segments sections T1-T10 (Pilowsky et al., 1992), they have ample chances to interrelate with the preganglionic cells that link indirectly with sympathetic nerve fibers surrounding the renal arteries. However, some other pathways might contribute to the trans-synaptic degeneration (Tsai et al., 2017), as the ganglion cells of renal afferent nerves in thoracic and lumbar spine dorsal root ganglia link to the posterior and lateral hypothalamic nuclei as well as the locus ceruleus in the brain stem (Campese and Kogosov, 1995; Jansen et al., 1995). RDN may affect the described connections and result in remodeling of the critical brainstem areas and the stellate ganglia. Because transneuronal degeneration may remain active for prolonged periods of time, the effects of RDN on arrhythmia control may persist for months after the procedure (Tsai et al., 2017).

\section{PV ISOLATION}

Pulmonary vein isolation with ganglionated plexi ablation has been used in autonomic modulation of interactions between the systemic and intrinsic cardiac ANS. PVI combined with autonomic ganglia modification significantly improved success rates after PVI compared to PVI alone (Katritsis et al., 2011). In animal models of vagal induced $\mathrm{AF}$, the effectiveness of pulmonary vein isolation was due to the ablation of the autonomic ganglia at the base of the pulmonary veins which eliminated rapid pulmonary vein firing in response to

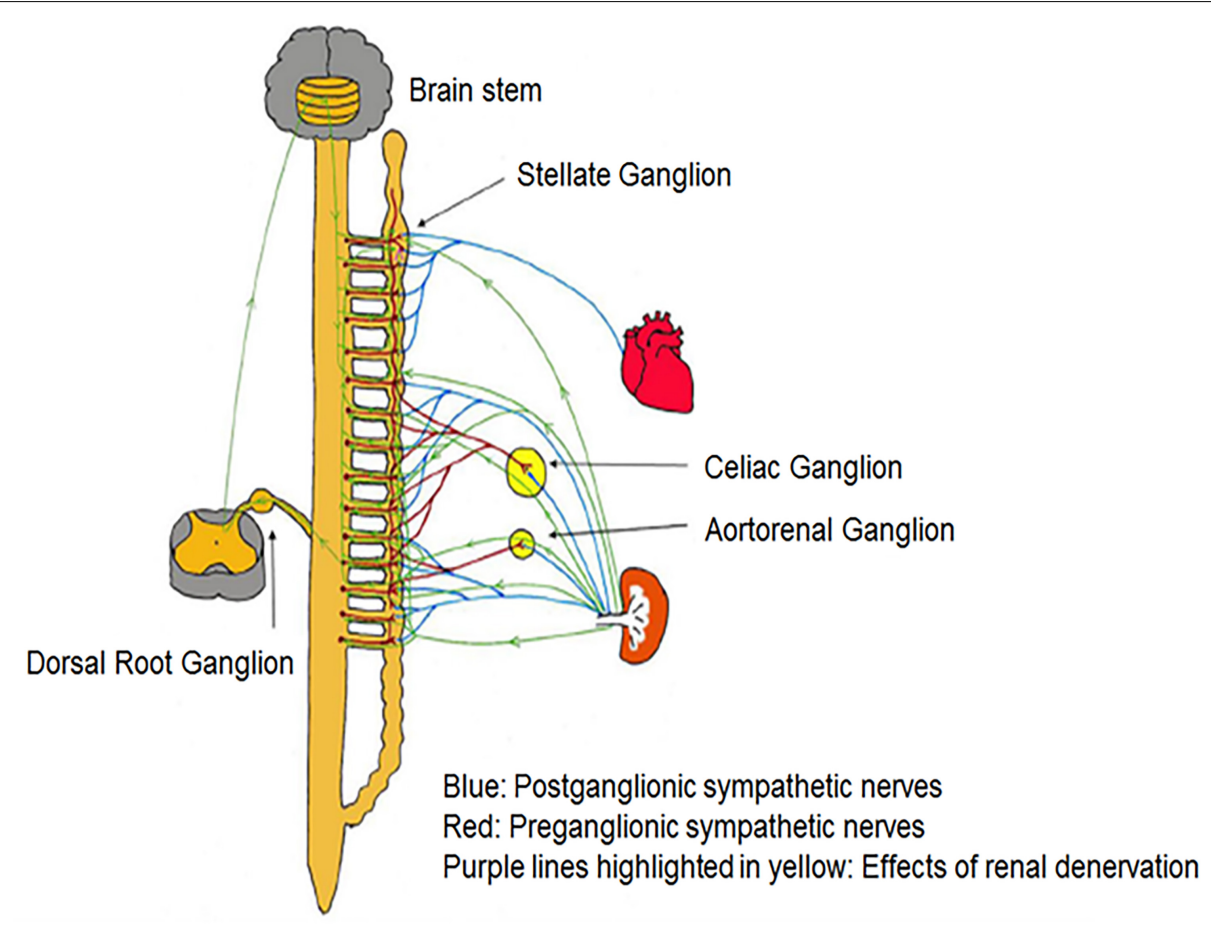

FIGURE 3 | There are multiple pathways connecting renal sympathetic nerves with the stellate ganglion. Both preganglionic and postganglionic sympathetic fibers may innervate the renal artery. 
high-frequency stimulation of the ganglionated plexi ( $\mathrm{Lu}$ et al., 2009). GP ablation inhibited AF inducibility in sleep apnea animal models (Ghias et al., 2009) and has been used in patients with both paroxysmal and persistent AF alone or combined with pulmonary vein isolation with better success rate in patients with paroxysmal AF (Pokushalov et al., 2009; Katritsis et al., 2011; Mikhaylov et al., 2011). However, though ganglionated plexi ablation appears to be a safe and efficacious adjunctive technique to improve outcomes of pulmonary vein isolation in patients with paroxysmal AF, GP ablation in animal models after acute myocardial ischemia exhibited ventricular arrhythmogenic effects compared with GP ablation of the normal heart (He et al., 2013). Hence further studies are warranted to investigate the application of these procedures in various cardiac conditions.

\section{BOTULINUM TOXIN INJECTION}

Recent studies have reported that an abundance of epicardial fat is associated with direct adipocyte infiltration into the underlying atrial myocardium (Hatem and Sanders, 2014; Mahajan et al., 2015). Moreover, increased overall adiposity has been shown to be associated with shortened effective refractory periods in the pulmonary veins, leading to the speculation that adiposity can predispose to AF initiation (Munger et al., 2012). Indeed, there is some evidence that areas of epicardial fat accumulation correlate with sites of high dominant frequency, suggesting that epicardial fat may influence AF triggers (Nagashima et al., 2012; Nakahara et al., 2014). Also, it may be possible that encasing epicardial fat influences ganglionated plexi and thus contributes to arrhythmogenesis. Recently, in a prospective, double-blind randomized controlled clinical trial (Pokushalov et al., 2015) reported that injections of botulinum toxin into epicardial fat pads in patients undergoing coronary artery bypass grafting $(\mathrm{CABG})$ resulted in a substantial reduction in the incidence of atrial tachyarrhythmia (most pronounced in the first 14 months postoperatively) and AF burden throughout the 3-year follow-up period, accompanied by reduction in need for hospitalization (Pokushalov et al., 2015; Romanov et al., 2018).

\section{STELLATE GANGLION BLOCKADE}

Studies demonstrate that stimulation of the stellate ganglion increased sinus rate and predisposes to atrial arrhythmias (Mohan et al., 2001; Tan et al., 2008a,b). Increased extrinsic cardiac nerve activity in the left stellate ganglion often preceded paroxysmal atrial tachycardia or AF in animal models (Choi et al., 2010). Unilateral electrical stimulation of the stellate ganglion aggravated atrial electrical remodeling facilitating induction of AF in animal models, an effect attenuated by unilateral ganglionectomy (Zhou et al., 2013). In animal models of pacing-induced congestive heart failure, cryoablation of bilateral stellate and T2-T4 thoracic ganglia reduced sympathetic activation-induced paroxysmal AF (Ogawa et al., 2009). Bilateral ANS remodeling resulting from the increased synaptic density of stellate ganglia following myocardial infarction was associated with increased ganglion activity (Han et al., 2012). Surgical excision of stellate ganglion (left cardiac sympathetic denervation) together with $\mathrm{T} 2$ and $\mathrm{T} 3$ thoracic ganglia reduced arrhythmia in high-risk patients and animal models following myocardial infarction (Schwartz et al., 1976, 1992) and in patients with catecholaminergic polymorphic ventricular tachycardia and long-QT syndrome (Collura et al., 2009).

\section{HIGH THORACIC EPIDURAL ANESTHESIA}

In patients undergoing cardiac surgery and cardiopulmonary bypass, high thoracic epidural anesthesia was found to markedly reduce sympathetic tone (Scott et al., 2001; Liu et al., 2004) and the risk of post-operative supraventricular arrhythmias (Svircevic et al., 2011). Initiation of high thoracic epidural anesthesia decreased the arrhythmia burden in patients with refractory electrical storm (Bourke et al., 2010) and in animal models of rapid atrial pacing was found to be associated with inhibition of atrial autonomic nerve sprouting (Yang et al., 2011). However variable results have been obtained pertaining to the decreased incidence of post-operative sustained AF despite a marked reduction in sympathetic activity (Groban et al., 2000; Jidéus et al., 2001) and warrants further detailed studies to explore the definitive effect of high thoracic epidural anesthesia on atrial electrophysiology and arrhythmogenesis.

\section{CAROTID BODY ABLATION}

Hypersensitive chemoreceptors result in sympathetic excitation. Enhanced chemoreflex sensitivity potentially increasing central sympathetic drive was observed in animal models of pacinginduced congestive heart failure (Schultz and Li, 2007). Surgical denervation of peripheral chemoreceptors prevented sympathetic activation- mediated hypertensive response to hypoxic stimuli in rats with intermittent hypoxia (Lesske et al., 1997). Bilateral denervation of the carotid body and the carotid sinus baroreceptors prevented the development of hypertension in young pre-hypertensive animals and significantly decreased arterial pressure in the adult population of spontaneously hypertensive rats (Tan et al., 2010) and hypertensive humans (Nakayama, 1961). Though carotid ablation appears as a logical approach to attenuate sympathetic overdrive, hypertension and arrhythmogenic atrial autonomic signaling in $\mathrm{AF}$, there are currently no studies characterizing its effects on atrial electrophysiology and atrial arrhythmogenesis.

\section{CONCLUSION AND PERSPECTIVES}

Enhanced sympathetic activation increases circulating catecholamines and causes hypertension and associated complication such as AF and congestive heart failure. Hypertension often coexists with comorbidities like obesity, 
metabolic syndrome, and obstructive sleep apnea that further exaggerate and sustain the sympathetic overdrive. Substantial evidence indicates that targeting sympathetic overactivity either by pharmacotherapy or device-based interventions seems to be a logical and useful approach for the management of AF. Sympathetic ablation by RDN appears to be a promising strategy to achieve atrial antiarrhythmic effects in animal models and humans. While carotid body ablation is a proven strategy to attenuate sympathetic overdrive, the potential antiarrhythmic effects are yet to be investigated in future studies. Other techniques employed to reduce sympathetic activity are applied in specific conditions such as stellate blockade in high-risk patients and following myocardial infarction,

\section{REFERENCES}

Abed, H. S., Wittert, G. A., Leong, D. P., Shirazi, M. G., Bahrami, B., Middeldorp, M. E., et al. (2013). Effect of weight reduction and cardiometabolic risk factor management on symptom burden and severity in patients with atrial fibrillation: a randomized clinical trial. JAMA 310, 2050-2060. doi: 10.1001/ jama.2013.280521

Aizer, A., Gaziano, J. M., Cook, N. R., Manson, J. E., Buring, J. E., and Albert, C. M. (2009). Relation of vigorous exercise to risk of atrial fibrillation. Am. J. Cardiol. 103, 1572-1577. doi: 10.1016/j.amjcard.2009.01.374

Al Chekakie, M. O., Welles, C. C., Metoyer, R., Ibrahim, A., Shapira, A. R., Cytron, J., et al. (2010). Pericardial fat is independently associated with human atrial fibrillation. J. Am. Coll. Cardiol. 56, 784-788. doi: 10.1016/j.jacc.2010. 03.071

Allessie, M., and de Groot, N. (2014). Crosstalk opposing view: rotors have not been demonstrated to be the drivers of atrial fibrillation. J. Physiol. 592, 3167-3170. doi: 10.1113/jphysiol.2014.271809

Allessie, M. A., Boyden, P. A., Camm, A. J., Kleber, A. G., Lab, M. J., Legato, M. J., et al. (2001). Pathophysiology and prevention of atrial fibrillation. Circulation 103, 769-777. doi: 10.1161/01.CIR.103.5.769

Allessie, M. A., de Groot, N. M., Houben, R. P., Schotten, U., Boersma, E., Smeets, J. L., et al. (2010). Electropathological substrate of long-standing persistent atrial fibrillation in patients with structural heart disease: longitudinal dissociation. Circ. Arrhythm. Electrophysiol. 3, 606-615. doi: 10.1161/CIRCEP.109. 910125

Alvarez, G. E., Beske, S. D., Ballard, T. P., and Davy, K. P. (2002). Sympathetic neural activation in visceral obesity. Circulation 106, 2533-2536. doi: 10.1161/ 01.CIR.0000041244.79165.25

Amar, D., Zhang, H., Miodownik, S., and Kadish, A. H. (2003). Competing autonomic mechanisms precede the onset of postoperative atrial fibrillation. J. Am. Coll. Cardiol. 42, 1262-1268. doi: 10.1016/S0735-1097(03)00 955-0

Andersson, T., Magnuson, A., Bryngelsson, I. L., Frobert, O., Henriksson, K. M., Edvardsson, N., et al. (2013). All-cause mortality in 272,186 patients hospitalized with incident atrial fibrillation 1995-2008: a Swedish nationwide long-term case-control study. Eur. Heart J. 34, 1061-1067. doi: 10.1093/ eurheartj/ehs469

Armour, J. A., Murphy, D. A., Yuan, B. X., Macdonald, S., and Hopkins, D. A. (1997). Gross and microscopic anatomy of the human intrinsic cardiac nervous system. Anat. Rec. 247, 289-298. doi: 10.1002/(SICI)1097-0185(199702)247: 2<289::AID-AR15>3.0.CO;2-L

Atienza, F., Almendral, J., Moreno, J., Vaidyanathan, R., Talkachou, A., Kalifa, J., et al. (2006). Activation of inward rectifier potassium channels accelerates atrial fibrillation in humans: evidence for a reentrant mechanism. Circulation 114, 2434-2442. doi: 10.1161/CIRCULATIONAHA.106.633735

Baber, U., Howard, V. J., Halperin, J. L., Soliman, E. Z., Zhang, X., McClellan, W., et al. (2011). Association of chronic kidney disease with atrial fibrillation among adults in the United States: REasons for Geographic and Racial Differences in Stroke (REGARDS) Study. Circ. Arrhythm. Electrophysiol. 4, 26-32. doi: 10.1161/CIRCEP.110.957100 ganglionic plexus ablation to lower AF recurrence in patients following circumferential pulmonary vein isolation, and high thoracic epidural anesthesia in post-surgical AF management. However further clinical studies are needed to substantiate the role of various sympatholytic approaches in the management of AF.

\section{AUTHOR CONTRIBUTIONS}

$\mathrm{RC}$ and MS have drafted the manuscript. MK, JH, and VM have researched data, contributed to inidvidual sections, and critically reviewed the manuscript.

Báez-Escudero, J. L., Keida, T., Dave, A. S., Okishige, K., and Valderrabano, M. (2014). Ethanol infusion in the vein of Marshall leads to parasympathetic denervation of the human left atrium: implications for atrial fibrillation. J. Am. Coll. Cardiol. 63, 1892-1901. doi: 10.1016/j.jacc.2014.01.032

Beukema, W. P., Sie, H. T., Misier, A. R., Delnoy, P. P., Wellens, H. J., and Elvan, A. (2008). Predictive factors of sustained sinus rhythm and recurrent atrial fibrillation after a radiofrequency modified Maze procedure. Eur. J. Cardiothorac. Surg. 34, 771-775. doi: 10.1016/j.ejcts.2008.07.026

Bohm, M., Kandzari, D., Townsend, R., Mahfoud, F., Weber, M., Fahy, M., et al. (2018). Spyral Htn-off med trial: changes in office and ambulatory heart rate. J. Hypertens. 36, e23-e24. doi: 10.1097/01.hjh.0000539024.31308.8d

Bourke, T., Vaseghi, M., Michowitz, Y., Sankhla, V., Shah, M., Swapna, N., et al. (2010). Neuraxial modulation for refractory ventricular arrhythmias: value of thoracic epidural anesthesia and surgical left cardiac sympathetic denervation. Circulation 121, 2255-2262. doi: 10.1161/CIRCULATIONAHA.109.929703

Bramlett, H. M., and Dietrich, W. D. (2007). Progressive damage after brain and spinal cord injury: pathomechanisms and treatment strategies. Prog. Brain Res. 161, 125-141. doi: 10.1016/S0079-6123(06)61009-1

Brandt, M. C., Mahfoud, F., Reda, S., Schirmer, S. H., Erdmann, E., Bohm, M., et al. (2012a). Renal sympathetic denervation reduces left ventricular hypertrophy and improves cardiac function in patients with resistant hypertension. J. Am. Coll. Cardiol. 59, 901-909. doi: 10.1016/j.jacc.2011.11.034

Brandt, M. C., Reda, S., Mahfoud, F., Lenski, M., Bohm, M., and Hoppe, U. C. (2012b). Effects of renal sympathetic denervation on arterial stiffness and central hemodynamics in patients with resistant hypertension. J. Am. Coll. Cardiol. 60, 1956-1965. doi: 10.1016/j.jacc.2012.08.959

Brignole, M., Gianfranchi, L., Menozzi, C., Raviele, A., Oddone, D., Lolli, G., et al. (1993). Role of autonomic reflexes in syncope associated with paroxysmal atrial fibrillation. J. Am. Coll. Cardiol. 22, 1123-1129. doi: 10.1016/0735-1097(93) 90426-2

Buch, P., Friberg, J., Scharling, H., Lange, P., and Prescott, E. (2003). Reduced lung function and risk of atrial fibrillation in the Copenhagen city heart study. Eur. Respir. J. 21, 1012-1016. doi: 10.1183/09031936.03.00051502

Cagnoni, F., Destro, M., Bontempelli, E., Locatelli, G., Hering, D., and Schlaich, M. P. (2016). Central sympathetic inhibition: a neglected approach for treatment of cardiac arrhythmias? Curr. Hypertens. Rep. 18:13. doi: 10.1007/ s11906-015-0619-0

Calkins, H., Kuck, K. H., Cappato, R., Brugada, J., Camm, A. J., Chen, S. A., et al. (2012). 2012 HRS/EHRA/ECAS expert consensus statement on catheter and surgical ablation of atrial fibrillation: recommendations for patient selection, procedural techniques, patient management and follow-up, definitions, endpoints, and research trial design. J. Interv. Card. Electrophysiol. 33, 171-257. doi: 10.1007/s10840-012-9672-7

Camm, A. J., Kirchhof, P., Lip, G. Y., Schotten, U., Savelieva, I., Ernst, S., et al. (2010). Guidelines for the management of atrial fibrillation: the task force for the management of Atrial Fibrillation of the European Society of Cardiology (ESC). Europace 12, 1360-1420. doi: 10.1093/europace/euq350

Campese, V. M., and Kogosov, E. (1995). Renal afferent denervation prevents hypertension in rats with chronic renal failure. Hypertension 25(4 Pt 2), 878-882. doi: 10.1161/01.HYP.25.4.878 
Chamberlain, A. M., Agarwal, S. K., Folsom, A. R., Duval, S., Soliman, E. Z., Ambrose, M., et al. (2011). Smoking and incidence of atrial fibrillation: results from the Atherosclerosis Risk in Communities (ARIC) study. Heart Rhythm 8, 1160-1166. doi: 10.1016/j.hrthm.2011.03.038

Chazova, I., Almazov, V. A., and Shlyakhto, E. (2006). Moxonidine improves glycaemic control in mildly hypertensive, overweight patients: a comparison with metformin. Diabetes Obes. Metab. 8, 456-465. doi: 10.1111/j.1463-1326. 2006.00606.x

Chen, P. S., and Tan, A. Y. (2007). Autonomic nerve activity and atrial fibrillation. Heart Rhythm 4(3 Suppl.), S61-S64. doi: 10.1016/j.hrthm.2006.12.006

Chen, S. A., Hsieh, M. H., Tai, C. T., Tsai, C. F., Prakash, V. S., Yu, W. C., et al. (1999). Initiation of atrial fibrillation by ectopic beats originating from the pulmonary veins: electrophysiological characteristics, pharmacological responses, and effects of radiofrequency ablation. Circulation 100, 1879-1886. doi: 10.1161/01.CIR.100.18.1879

Chen, J., Mandapati, R., Berenfeld, O., Skanes, A. C., Gray, R. A., and Jalife, J. (2000). Dynamics of wavelets and their role in atrial fibrillation in the isolated sheep heart. Cardiovasc. Res. 48, 220-232.

Chevalier, P., Tabib, A., Meyronnet, D., Chalabreysse, L., Restier, L., Ludman, V., et al. (2005). Quantitative study of nerves of the human left atrium. Heart Rhythm 2, 518-522. doi: 10.1016/j.hrthm.2005.01.022

Choi, E. K., Shen, M. J., Han, S., Kim, D., Hwang, S., Sayfo, S., et al. (2010). Intrinsic cardiac nerve activity and paroxysmal atrial tachyarrhythmia in ambulatory dogs. Circulation 121, 2615-2623. doi: 10.1161/CIRCULATIONAHA.109. 919829

Christ, T., Rozmaritsa, N., Engel, A., Berk, E., Knaut, M., Metzner, K., et al. (2014). Arrhythmias, elicited by catecholamines and serotonin, vanish in human chronic atrial fibrillation. Proc. Natl. Acad. Sci. U.S.A. 111, 11193-11198. doi: 10.1073/pnas.1324132111

Collura, C. A., Johnson, J. N., Moir, C., and Ackerman, M. J. (2009). Left cardiac sympathetic denervation for the treatment of long QT syndrome and catecholaminergic polymorphic ventricular tachycardia using video-assisted thoracic surgery. Heart Rhythm 6, 752-759. doi: 10.1016/j.hrthm.2009.03.024

Coumel, P. (1996). Autonomic influences in atrial tachyarrhythmias. J. Cardiovasc. Electrophysiol. 7, 999-1007. doi: 10.1111/j.1540-8167.1996.tb00474.x

Cox, J. L., Canavan, T. E., Schuessler, R. B., Cain, M. E., Lindsay, B. D., Stone, C., et al. (1991). The surgical treatment of atrial fibrillation. II. Intraoperative electrophysiologic mapping and description of the electrophysiologic basis of atrial flutter and atrial fibrillation. J. Thorac. Cardiovasc. Surg. 101, 406-426.

de Groot, N. M., Houben, R. P., Smeets, J. L., Boersma, E., Schotten, U., Schalij, M. J., et al. (2010). Electropathological substrate of longstanding persistent atrial fibrillation in patients with structural heart disease: epicardial breakthrough. Circulation 122, 1674-1682. doi: 10.1161/CIRCULATIONAHA.109.910901

Deftereos, S., Giannopoulos, G., Kossyvakis, C., Efremidis, M., Panagopoulou, V., Raisakis, K., et al. (2013). Effectiveness of moxonidine to reduce atrial fibrillation burden in hypertensive patients. Am. J. Cardiol. 112, 684-687. doi: 10.1016/j.amjcard.2013.04.049

Deneke, T., Chaar, H., de Groot, J. R., Wilde, A. A., Lawo, T., Mundig, J., et al. (2011). Shift in the pattern of autonomic atrial innervation in subjects with persistent atrial fibrillation. Heart Rhythm 8, 1357-1363. doi: 10.1016/j.hrthm. 2011.04.013

Di Biase, L., Burkhardt, J. D., Mohanty, P., Sanchez, J., Mohanty, S., Horton, R., et al. (2010). Left atrial appendage: an underrecognized trigger site of atrial fibrillation. Circulation 122, 109-118. doi: 10.1161/CIRCULATIONAHA.109. 928903

Dimitri, H., Ng, M., Brooks, A. G., Kuklik, P., Stiles, M. K., Lau, D. H., et al. (2012). Atrial remodeling in obstructive sleep apnea: implications for atrial fibrillation. Heart Rhythm 9, 321-327. doi: 10.1016/j.hrthm.2011.10.017

Dimmer, C., Tavernier, R., Gjorgov, N., Van Nooten, G., Clement, D. L., and Jordaens, L. (1998). Variations of autonomic tone preceding onset of atrial fibrillation after coronary artery bypass grafting. Am. J. Cardiol. 82, 22-25. doi: 10.1016/S0002-9149(98)00231-8

Dizon, J. M., Chen, K., Bacchetta, M., Argenziano, M., Mancini, D., Biviano, A., et al. (2009). A comparison of atrial arrhythmias after heart or double-lung transplantation at a single center: insights into the mechanism of post-operative atrial fibrillation. J. Am. Coll. Cardiol. 54, 2043-2048. doi: 10.1016/j.jacc.2009. 08.029
Dobrev, D., Friedrich, A., Voigt, N., Jost, N., Wettwer, E., Christ, T., et al. (2005). The $\mathrm{G}$ protein-gated potassium current $\mathrm{I}(\mathrm{K}, \mathrm{ACh})$ is constitutively active in patients with chronic atrial fibrillation. Circulation 112, 3697-3706. doi: 10. 1161/CIRCULATIONAHA.105.575332

Eckstein, J., Maesen, B., Linz, D., Zeemering, S., van Hunnik, A., Verheule, S., et al. (2011). Time course and mechanisms of endo-epicardial electrical dissociation during atrial fibrillation in the goat. Cardiovasc. Res. 89, 816-824. doi: 10.1093/ cvr/cvq336

Edwards, L. P., Brown-Bryan, T. A., McLean, L., and Ernsberger, P. (2012). Pharmacological properties of the central antihypertensive agent, moxonidine. Cardiovasc. Ther. 30, 199-208. doi: 10.1111/j.1755-5922.2011.00268.x

Ehrlich, J. R., Hohnloser, S. H., and Nattel, S. (2006). Role of angiotensin system and effects of its inhibition in atrial fibrillation: clinical and experimental evidence. Eur. Heart J. 27, 512-518. doi: 10.1093/eurheartj/ehi668

Esler, M. (2004). Looking at the sympathetic nervous system as a primary source. Handb. Hypertens. 22, 81-102.

Esler, M., Alvarenga, M., Pier, C., Richards, J., El-Osta, A., Barton, D., et al. (2006a). The neuronal noradrenaline transporter, anxiety and cardiovascular disease. J. Psychopharmacol. 20(4 Suppl.), 60-66. doi: 10.1177/13597868060 66055

Esler, M., Straznicky, N., Eikelis, N., Masuo, K., Lambert, G., and Lambert, E. (2006b). Mechanisms of sympathetic activation in obesity-related hypertension. Hypertension 48, 787-796. doi: 10.1161/01.HYP.0000242642. 42177.49

Ferguson, M., Ryan, G. B., and Bell, C. (1986). Localization of sympathetic and sensory neurons innervating the rat kidney. J. Auton Nerv. Syst. 16, 279-288. doi: 10.1016/0165-1838(86)90034-2

Feyz, L., Theuns, D. A., Bhagwandien, R., Strachinaru, M., Kardys, I., Van Mieghem, N. M., et al. (2018). Atrial fibrillation reduction by renal sympathetic denervation: 12 months' results of the AFFORD study. Clin. Res. Cardiol. doi: 10.1007/s00392-018-1391-3 [Epub ahead of print].,

Flacke, J. W., Bloor, B. C., Flacke, W. E., Wong, D., Dazza, S., Stead, S. W., et al. (1987). Reduced narcotic requirement by clonidine with improved hemodynamic and adrenergic stability in patients undergoing coronary bypass surgery. Anesthesiology 67, 11-19. doi: 10.1097/00000542-198707000-0 0003

Furukawa, T., Hirao, K., Horikawa-Tanami, T., Hachiya, H., and Isobe, M. (2009). Influence of autonomic stimulation on the genesis of atrial fibrillation in remodeled canine atria not the same as in normal atria. Circ. J. 73, 468-475. doi: 10.1253/circj.CJ-08-0869

Gami, A. S., Hodge, D. O., Herges, R. M., Olson, E. J., Nykodym, J., Kara, T., et al. (2007). Obstructive sleep apnea, obesity, and the risk of incident atrial fibrillation. J. Am. Coll. Cardiol. 49, 565-571. doi: 10.1016/j.jacc.2006. 08.060

Gattone, V. H. II, Marfurt, C. F., and Dallie, S. (1986). Extrinsic innervation of the rat kidney: a retrograde tracing study. Am. J. Physiol. 250(2 Pt 2), F189-F196. doi: 10.1152/ajprenal.1986.250.2.F189

Ghias, M., Scherlag, B. J., Lu, Z., Niu, G., Moers, A., Jackman, W. M., et al. (2009). The role of ganglionated plexi in apnea-related atrial fibrillation. J. Am. Coll. Cardiol. 54, 2075-2083. doi: 10.1016/j.jacc.2009.09.014

Giannopoulos, G., Kossyvakis, C., Efremidis, M., Katsivas, A., Panagopoulou, V., Doudoumis, K., et al. (2014). Central sympathetic inhibition to reduce postablation atrial fibrillation recurrences in hypertensive patients: a randomized, controlled study. Circulation 130, 1346-1352. doi: 10.1161/CIRCULATIONAHA.114.010999

Girerd, N., Magne, J., Pibarot, P., Voisine, P., Dagenais, F., and Mathieu, P. (2011). Postoperative atrial fibrillation predicts long-term survival after aortic-valve surgery but not after mitral-valve surgery: a retrospective study. BMJ Open 1:e000385. doi: 10.1136/bmjopen-2011-000385

Goette, A., Staack, T., Rocken, C., Arndt, M., Geller, J. C., Huth, C., et al. (2000). Increased expression of extracellular signal-regulated kinase and angiotensinconverting enzyme in human atria during atrial fibrillation. J. Am. Coll. Cardiol. 35, 1669-1677. doi: 10.1016/S0735-1097(00)00611-2

Gould, P. A., Yii, M., McLean, C., Finch, S., Marshall, T., Lambert, G. W., et al. (2006). Evidence for increased atrial sympathetic innervation in persistent human atrial fibrillation. Pacing Clin. Electrophysiol. 29, 821-829. doi: 10.1111/ j.1540-8159.2006.00447.x 
Grassi, G., Seravalle, G., Cattaneo, B. M., Bolla, G. B., Lanfranchi, A., Colombo, M., et al. (1995). Sympathetic activation in obese normotensive subjects. Hypertension 25(4 Pt 1), 560-563. doi: 10.1161/01.HYP.25.4.560

Greiser, M., Kerfant, B. G., Williams, G. S., Voigt, N., Harks, E., Dibb, K. M., et al. (2014). Tachycardia-induced silencing of subcellular Ca2+ signaling in atrial myocytes. J. Clin. Invest. 124, 4759-4772. doi: 10.1172/JCI70102

Groban, L., Dolinski, S. Y., Zvara, D. A., and Oaks, T. (2000). Thoracic epidural analgesia: its role in postthoracotomy atrial arrhythmias. J. Cardiothorac. Vasc. Anesth. 14, 662-665. doi: 10.1053/jcan.2000.18318

Haenni, A., and Lithell, H. (1999). Moxonidine improves insulin sensitivity in insulin-resistant hypertensives. J. Hypertens. 17, S29-S35.

Haissaguerre, M., Hocini, M., Denis, A., Shah, A. J., Komatsu, Y., Yamashita, S., et al. (2014). Driver domains in persistent atrial fibrillation. Circulation 130, 530-538. doi: 10.1161/CIRCULATIONAHA.113.005421

Haissaguerre, M., Jais, P., Shah, D. C., Takahashi, A., Hocini, M., Quiniou, G., et al. (1998). Spontaneous initiation of atrial fibrillation by ectopic beats originating in the pulmonary veins. N. Engl. J. Med. 339, 659-666. doi: 10.1056/ NEJM199809033391003

Haissaguerre, M., Sanders, P., Hocini, M., Takahashi, Y., Rotter, M., Sacher, F., et al. (2005). Catheter ablation of long-lasting persistent atrial fibrillation: critical structures for termination. J. Cardiovasc. Electrophysiol. 16, 1125-1137. doi: 10.1111/j.1540-8167.2005.00307.x

Han, S., Kobayashi, K., Joung, B., Piccirillo, G., Maruyama, M., Vinters, H. V., et al. (2012). Electroanatomic remodeling of the left stellate ganglion after myocardial infarction. J. Am. Coll. Cardiol. 59, 954-961. doi: 10.1016/j.jacc.2011.11.030

Hatem, S. N., and Sanders, P. (2014). Epicardial adipose tissue and atrial fibrillation. Cardiovasc. Res. 102, 205-213. doi: 10.1093/cvr/cvu045

He, B., Lu, Z., He, W., Wu, L., Cui, B., Hu, X., et al. (2013). Effects of ganglionated plexi ablation on ventricular electrophysiological properties in normal hearts and after acute myocardial ischemia. Int. J. Cardiol. 168, 86-93. doi: 10.1016/j. ijcard.2012.09.067

Hou, Y., Hu, J., Po, S. S., Wang, H., Zhang, L., Zhang, F., et al. (2013). Catheterbased renal sympathetic denervation significantly inhibits atrial fibrillation induced by electrical stimulation of the left stellate ganglion and rapid atrial pacing. PLoS One 8:e78218. doi: 10.1371/journal.pone.0078218

Hou, Y., Scherlag, B. J., Lin, J., Zhou, J., Song, J., Zhang, Y., et al. (2007). Interactive atrial neural network: determining the connections between Ganglionated plexi. Heart Rhythm 4, 56-63. doi: 10.1016/j.hrthm.2006.09.020

Huggett, R. J., Burns, J., Mackintosh, A. F., and Mary, D. A. (2004). Sympathetic neural activation in nondiabetic metabolic syndrome and its further augmentation by hypertension. Hypertension 44, 847-852. doi: 10.1161/ 01.HYP.0000147893.08533.d8

Huggett, R. J., Hogarth, A. J., Mackintosh, A. F., and Mary, D. A. (2006). Sympathetic nerve hyperactivity in non-diabetic offspring of patients with type 2 diabetes mellitus. Diabetologia 49, 2741-2744. doi: 10.1007/s00125-006-03999

Iacobellis, G., Ribaudo, M. C., Assael, F., Vecci, E., Tiberti, C., Zappaterreno, A., et al. (2003). Echocardiographic epicardial adipose tissue is related to anthropometric and clinical parameters of metabolic syndrome: a new indicator of cardiovascular risk. J. Clin. Endocrinol. Metab. 88, 5163-5168. doi: 10.1210/ jc.2003-030698

Iwasaki, Y. K., Nishida, K., Kato, T., and Nattel, S. (2011). Atrial fibrillation pathophysiology: implications for management. Circulation 124, 2264-2274. doi: 10.1161/CIRCULATIONAHA.111.019893

Jalife, J., Berenfeld, O., and Mansour, M. (2002). Mother rotors and fibrillatory conduction: a mechanism of atrial fibrillation. Cardiovasc. Res. 54, 204-216. doi: 10.1016/S0008-6363(02)00223-7

Jansen, A. S., Wessendorf, M. W., and Loewy, A. D. (1995). Transneuronal labeling of CNS neuropeptide and monoamine neurons after pseudorabies virus injections into the stellate ganglion. Brain Res. 683, 1-24. doi: 10.1016/00068993(95)00276-V

Jayachandran, J. V., Sih, H. J., Winkle, W., Zipes, D. P., Hutchins, G. D., and Olgin, J. E. (2000). Atrial fibrillation produced by prolonged rapid atrial pacing is associated with heterogeneous changes in atrial sympathetic innervation. Circulation 101, 1185-1191. doi: 10.1161/01.CIR.101. 10.1185

Jideus, L., Joachimsson, P. O., Stridsberg, M., Ericson, M., Tyden, H., Nilsson, L., et al. (2001). Thoracic epidural anesthesia does not influence the occurrence of postoperative sustained atrial fibrillation. Ann. Thorac. Surg. 72, 65-71. doi: 10.1016/S0003-4975(01)02631-5

Julius, S., and Jamerson, K. (1994). Sympathetics, insulin resistance and coronary risk in hypertension: the 'chicken-and-egg' question. J. Hypertens. 12, 495-502. doi: 10.1097/00004872-199405000-00001

Kalman, J. M., Munawar, M., Howes, L. G., Louis, W. J., Buxton, B. F., Gutteridge, G., et al. (1995). Atrial fibrillation after coronary artery bypass grafting is associated with sympathetic activation. Ann. Thorac. Surg. 60, 1709-1715. doi: 10.1016/0003-4975(95)00718-0

Katritsis, D. G., Giazitzoglou, E., Zografos, T., Pokushalov, E., Po, S. S., and Camm, A. J. (2011). Rapid pulmonary vein isolation combined with autonomic ganglia modification: a randomized study. Heart Rhythm 8, 672-678. doi: 10.1016/j. hrthm.2010.12.047

Kawano, H., Okada, R., and Yano, K. (2003). Histological study on the distribution of autonomic nerves in the human heart. Heart Vessel 18, 32-39. doi: 10.1007/ s003800300005

Kawashima, T. (2005). The autonomic nervous system of the human heart with special reference to its origin, course, and peripheral distribution. Anat. Embryol. 209, 425-438. doi: 10.1007/s00429-005-0462-1

Kim, D. T., Lai, A. C., Hwang, C., Fan, L. T., Karagueuzian, H. S., Chen, P. S., et al. (2000). The ligament of Marshall: a structural analysis in human hearts with implications for atrial arrhythmias. J. Am. Coll. Cardiol. 36, 1324-1327. doi: 10.1016/S0735-1097(00)00819-6

Kim, E. J., Lyass, A., Wang, N., Massaro, J. M., Fox, C. S., Benjamin, E. J., et al. (2014). Relation of hypothyroidism and incident atrial fibrillation (from the Framingham Heart Study). Am. Heart. J. 167, 123-126. doi: 10.1016/j.ahj.2013. 10.012

Kimura, K., Ieda, M., and Fukuda, K. (2012). Development, maturation, and transdifferentiation of cardiac sympathetic nerves. Circ. Res. 110, 325-336. doi: 10.1161/CIRCRESAHA.111.257253

Kirchhof, P., Benussi, S., Kotecha, D., Ahlsson, A., Atar, D., Casadei, B., et al. (2016). 2016 ESC guidelines for the management of atrial fibrillation developed in collaboration with EACTS. Eur. Heart J. 37, 2893-2962. doi: 10.1093/ eurheartj/ehw210

Kiuchi, M. G., Chen, S., E Silver, G. R., Rodrigues Paz, L. M., Kiuchi, T., de Paula Filho, A. G., et al. (2017). The addition of renal sympathetic denervation to pulmonary vein isolation reduces recurrence of paroxysmal atrial fibrillation in chronic kidney disease patients. J. Interv. Card. Electrophysiol. 48, 215-222. doi: 10.1007/s10840-016-0186-6

Krum, H., Schlaich, M., Whitbourn, R., Sobotka, P. A., Sadowski, J., Bartus, K., et al. (2009). Catheter-based renal sympathetic denervation for resistant hypertension: a multicentre safety and proof-of-principle cohort study. Lancet 373, 1275-1281. doi: 10.1016/S0140-6736(09)60566-3

Kühlkamp, V., Schirdewan, A., Stangl, K., Homberg, M., Ploch, M., and Beck, O. A. (2000). Use of metoprolol CR/XL to maintain sinus rhythm after conversion from persistent atrial fibrillation: a randomized, double-blind, placebo-controlled study. J. Am. Coll. Cardiol. 36, 139-146. doi: 10.1016/S07351097(00)00693-8

Kumagai, K., Nakashima, H., Urata, H., Gondo, N., Arakawa, K., and Saku, K. (2003). Effects of angiotensin II type 1 receptor antagonist on electrical and structural remodeling in atrial fibrillation. J. Am. Coll. Cardiol. 41, 2197-2204. doi: 10.1016/S0735-1097(03)00464-9

Lambert, E., Eikelis, N., Esler, M., Dawood, T., Schlaich, M., Bayles, R., et al. (2008). Altered sympathetic nervous reactivity and norepinephrine transporter expression in patients with postural tachycardia syndrome. Circ. Arrhythm Electrophysiol. 1, 103-109. doi: 10.1161/CIRCEP.107.750471

Lambert, E., Sari, C. I., Dawood, T., Nguyen, J., McGrane, M., Eikelis, N., et al. (2010). Sympathetic nervous system activity is associated with obesity-induced subclinical organ damage in young adults. Hypertension 56, 351-358. doi: 10. 1161/HYPERTENSIONAHA.110.155663

Lambert, E., Straznicky, N., Eikelis, N., Esler, M., Dawood, T., Masuo, K., et al. (2007). Gender differences in sympathetic nervous activity: influence of body mass and blood pressure. J. Hypertens. 25, 1411-1419. doi: 10.1097/HJH. 0b013e3281053af4

Lambert, E. A., Thompson, J., Schlaich, M., Laude, D., Elghozi, J. L., Esler, M. D., et al. (2002). Sympathetic and cardiac baroreflex function in panic disorder. J. Hypertens. 20, 2445-2451. doi: 10.1097/01.hjh.0000042882.24 999.27 
Langer, S. Z., Cavero, I., and Massingham, R. (1980). Recent developments in noradrenergic neurotransmission and its relevance to the mechanism of action of certain antihypertensive agents. Hypertension 2, 372-382. doi: 10.1161/01. HYP.2.4.372

Larsson, S. C., Drca, N., and Wolk, A. (2014). Alcohol consumption and risk of atrial fibrillation: a prospective study and dose-response meta-analysis. J. Am. Coll. Cardiol. 64, 281-289. doi: 10.1016/j.jacc.2014.03.048

Lau, D. H., Mackenzie, L., Kelly, D. J., Psaltis, P. J., Brooks, A. G., Worthington, M., et al. (2010). Hypertension and atrial fibrillation: evidence of progressive atrial remodeling with electrostructural correlate in a conscious chronically instrumented ovine model. Heart Rhythm 7, 1282-1290. doi: 10.1016/j.hrthm. 2010.05.010

Lepran, I., and Papp, J. G. (1994). Effect of moxonidine on arrhythmias induced by coronary artery occlusion and reperfusion. J. Cardiovasc. Pharmacol. 24(Suppl. 1), S9-S15. doi: 10.1097/00005344-199424001-00003

Lesske, J., Fletcher, E. C., Bao, G., and Unger, T. (1997). Hypertension caused by chronic intermittent hypoxia-influence of chemoreceptors and sympathetic nervous system. J. Hypertens. 15(12 Pt 2), 1593-1603.

Li, D., Fareh, S., Leung, T. K., and Nattel, S. (1999). Promotion of atrial fibrillation by heart failure in dogs: atrial remodeling of a different sort. Circulation 100, 87-95. doi: 10.1161/01.CIR.100.1.87

Lim, P. B., Malcolme-Lawes, L. C., Stuber, T., Wright, I., Francis, D. P., Davies, D. W., et al. (2011). Intrinsic cardiac autonomic stimulation induces pulmonary vein ectopy and triggers atrial fibrillation in humans. J. Cardiovasc. Electrophysiol. 22, 638-646. doi: 10.1111/j.1540-8167.2010.01992.x

Linz, D., Hohl, M., Nickel, A., Mahfoud, F., Wagner, M., Ewen, S., et al. (2013a). Effect of renal denervation on neurohumoral activation triggering atrial fibrillation in obstructive sleep apnea. Hypertension 62, 767-774. doi: 10.1161/HYPERTENSIONAHA.113.01728

Linz, D., Mahfoud, F., Schotten, U., Ukena, C., Hohl, M., Neuberger, H. R., et al. (2013b). Renal sympathetic denervation provides ventricular rate control but does not prevent atrial electrical remodeling during atrial fibrillation. Hypertension 61, 225-231. doi: 10.1161/HYPERTENSIONAHA.111.00182

Linz, D., Mahfoud, F., Schotten, U., Ukena, C., Neuberger, H. R., Wirth, K., et al. (2012). Renal sympathetic denervation suppresses postapneic blood pressure rises and atrial fibrillation in a model for sleep apnea. Hypertension 60, 172-178. doi: 10.1161/HYPERTENSIONAHA.112.191965

Liu, S. S., Block, B. M., and Wu, C. L. (2004). Effects of perioperative central neuraxial analgesia on outcome after coronary artery bypass surgery: a metaanalysis. Anesthesiology 101, 153-161. doi: 10.1097/00000542-20040700000024

Lu, Z., Scherlag, B. J., Lin, J., Niu, G., Ghias, M., Jackman, W. M., et al. (2008). Autonomic mechanism for complex fractionated atrial electrograms: evidence by fast fourier transform analysis. J. Cardiovasc. Electrophysiol. 19, 835-842. doi: 10.1111/j.1540-8167.2008.01131.x

Lu, Z., Scherlag, B. J., Lin, J., Yu, L., Guo, J. H., Niu, G., et al. (2009). Autonomic mechanism for initiation of rapid firing from atria and pulmonary veins: evidence by ablation of ganglionated plexi. Cardiovasc. Res. 84, 245-252. doi: $10.1093 / \mathrm{cvr} / \mathrm{cvp} 194$

Lubitz, S. A., Lunetta, K. L., Lin, H., Arking, D. E., Trompet, S., Li, G., et al. (2014). Novel genetic markers associate with atrial fibrillation risk in Europeans and Japanese. J. Am. Coll. Cardiol. 63, 1200-1210. doi: 10.1016/j.jacc.2013.12.015

Mahabadi, A. A., Massaro, J. M., Rosito, G. A., Levy, D., Murabito, J. M., Wolf, P. A., et al. (2009). Association of pericardial fat, intrathoracic fat, and visceral abdominal fat with cardiovascular disease burden: the Framingham Heart Study. Eur. Heart J. 30, 850-856. doi: 10.1093/eurheartj/ehn573

Mahajan, R., Lau, D. H., Brooks, A. G., Shipp, N. J., Manavis, J., Wood, J. P., et al. (2015). Electrophysiological, electroanatomical, and structural remodeling of the Atria as consequences of sustained obesity. J. Am. Coll. Cardiol. 66, 1-11. doi: $10.1016 /$ j.jacc.2015.04.058

Mahfoud, F., Schlaich, M., Kindermann, I., Ukena, C., Cremers, B., Brandt, M. C., et al. (2011). Effect of renal sympathetic denervation on glucose metabolism in patients with resistant hypertension: a pilot study. Circulation 123, 1940-1946. doi: 10.1161/CIRCULATIONAHA.110.991869

Malcolme-Lawes, L. C., Lim, P. B., Wright, I., Kojodjojo, P., Koa-Wing, M., JamilCopley, S., et al. (2013). Characterization of the left atrial neural network and its impact on autonomic modification procedures. Circ. Arrhythm Electrophysiol. 6, 632-640. doi: 10.1161/CIRCEP.113.000193
Mandapati, R., Skanes, A., Chen, J., Berenfeld, O., and Jalife, J. (2000). Stable microreentrant sources as a mechanism of atrial fibrillation in the isolated sheep heart. Circulation 101, 194-199. doi: 10.1161/01.CIR.101.2.194

Manolis, A. J., Rosei, E. A., Coca, A., Cifkova, R., Erdine, S. E., Kjeldsen, S., et al. (2012). Hypertension and atrial fibrillation: diagnostic approach, prevention and treatment. Position paper of the Working Group 'Hypertension Arrhythmias and Thrombosis' of the European Society of Hypertension. J. Hypertens. 30, 239-252. doi: 10.1097/HJH.0b013e32834f03bf

Marron, K., Wharton, J., Sheppard, M. N., Fagan, D., Royston, D., Kuhn, D. M., et al. (1995). Distribution, morphology, and neurochemistry of endocardial and epicardial nerve terminal arborizations in the human heart. Circulation 92, 2343-2351. doi: 10.1161/01.CIR.92.8.2343

Marron, K., Wharton, J., Sheppard, M. N., Gulbenkian, S., Royston, D., Yacoub, M. H., et al. (1994). Human endocardial innervation and its relationship to the endothelium: an immunohistochemical, histochemical, and quantitative study. Cardiovasc. Res. 28, 1490-1499. doi: 10.1093/cvr/28.10.1490

Matthews, V. B., Elliot, R. H., Rudnicka, C., Hricova, J., Herat, L., and Schlaich, M. P. (2017). Role of the sympathetic nervous system in regulation of the sodium glucose cotransporter 2. J. Hypertens. 35, 2059-2068. doi: 10.1097/HJH. 0000000000001434

McLellan, A. J., Schlaich, M. P., Taylor, A. J., Prabhu, S., Hering, D., Hammond, L., et al. (2015). Reverse cardiac remodeling after renal denervation: atrial electrophysiologic and structural changes associated with blood pressure lowering. Heart Rhythm 12, 982-990. doi: 10.1016/j.hrthm.2015.01.039

Meckler, R. L., and Weaver, L. C. (1984). Comparison of the distributions of renal and splenic neurons in sympathetic ganglia. J. Auton Nerv. Syst. 11, 189-200. doi: 10.1016/0165-1838(84)90076-6

Melo, J., Voigt, P., Sonmez, B., Ferreira, M., Abecasis, M., Rebocho, M., et al. (2004). Ventral cardiac denervation reduces the incidence of atrial fibrillation after coronary artery bypass grafting. J. Thorac. Cardiovasc. Surg. 127, 511-516. doi: 10.1016/S0022

Mest, H. J., Thomsen, P., and Raap, A. (1995). Antiarrhythmic effect of the selective I1-imidazoline receptor modulator moxonidine on ouabain-induced cardiac arrhythmia in guinea pigs. Ann. N. Y. Acad. Sci. 763, 620-633. doi: 10.1111/j. 1749-6632.1995.tb32457.x

Mikhaylov, E., Kanidieva, A., Sviridova, N., Abramov, M., Gureev, S., SziliTorok, T., et al. (2011). Outcome of anatomic ganglionated plexi ablation to treat paroxysmal atrial fibrillation: a 3-year follow-up study. Europace 13, 362-370. doi: 10.1093/europace/euq416

Moe, G. K., and Abildskov, J. A. (1959). Atrial fibrillation as a self-sustaining arrhythmia independent of focal discharge. Am. Heart. J. 58, 59-70. doi: 10. 1016/0002-8703(59)90274- 1

Moe, G. K., Rheinboldt, W. C., and Abildskov, J. A. (1964). A computer model of atrial fibrillation. Am. Heart J. 67, 200-220. doi: 10.1016/0002-8703(64)90371-0

Mohan, R. M., Golding, S., and Paterson, D. J. (2001). Intermittent hypoxia modulates nNOS expression and heart rate response to sympathetic nerve stimulation. Am. J. Physiol. Heart Circ. Physiol. 281, H132-H138. doi: 10.1152/ ajpheart.2001.281.1.H132

Munger, T. M., Dong, Y. X., Masaki, M., Oh, J. K., Mankad, S. V., Borlaug, B. A., et al. (2012). Electrophysiological and hemodynamic characteristics associated with obesity in patients with atrial fibrillation. J. Am. Coll. Cardiol. 60, 851-860. doi: 10.1016/j.jacc.2012.03.042

Nagashima, K., Okumura, Y., Watanabe, I., Nakai, T., Ohkubo, K., Kofune, M., et al. (2012). Does location of epicardial adipose tissue correspond to endocardial high dominant frequency or complex fractionated atrial electrogram sites during atrial fibrillation? Circ. Arrhythm Electrophysiol. 5, 676-683. doi: 10.1161/CIRCEP.112.971200

Nakahara, S., Hori, Y., Kobayashi, S., Sakai, Y., Taguchi, I., Takayanagi, K., et al. (2014). Epicardial adipose tissue-based defragmentation approach to persistent atrial fibrillation: its impact on complex fractionated electrograms and ablation outcome. Heart Rhythm 11, 1343-1351. doi: 10.1016/j.hrthm.2014.04.040

Nakayama, K. (1961). Surgical removal of the carotid body for bronchial asthma. Dis. Chest 40, 595-604. doi: 10.1378/chest.40.6.595

Narayan, S. M., Krummen, D. E., Shivkumar, K., Clopton, P., Rappel, W. J., and Miller, J. M. (2012). Treatment of atrial fibrillation by the ablation of localized sources: CONFIRM (Conventional Ablation for Atrial Fibrillation With or Without Focal Impulse and Rotor Modulation) trial. J. Am. Coll. Cardiol. 60, 628-636. doi: 10.1016/j.jacc.2012.05.022 
Nattel, S. (2002). New ideas about atrial fibrillation 50 years on. Nature 415, 219-226. doi: 10.1038/415219a

Nergårdh, A. K., Rosenqvist, M., Nordlander, R., and Frick, M. (2007). Maintenance of sinus rhythm with metoprolol CR initiated before cardioversion and repeated cardioversion of atrial fibrillation: a randomized double-blind placebo-controlled study. Eur. Heart J. 28, 1351-1357. doi: 10.1093/eurheartj/ehl544

Ng, J., Villuendas, R., Cokic, I., Schliamser, J. E., Gordon, D., Koduri, H., et al. (2011). Autonomic remodeling in the left atrium and pulmonary veins in heart failure: creation of a dynamic substrate for atrial fibrillation. Circ. Arrhythm Electrophysiol. 4, 388-396. doi: 10.1161/CIRCEP.110.959650

Nguyen, B. L., Fishbein, M. C., Chen, L. S., Chen, P. S., and Masroor, S. (2009). Histopathological substrate for chronic atrial fibrillation in humans. Heart Rhythm 6, 454-460. doi: 10.1016/j.hrthm.2009.01.010

Ogawa, M., Tan, A. Y., Song, J., Kobayashi, K., Fishbein, M. C., Lin, S. F., et al. (2009). Cryoablation of stellate ganglia and atrial arrhythmia in ambulatory dogs with pacing-induced heart failure. Heart Rhythm 6, 1772-1779. doi: 10. 1016/j.hrthm.2009.08.011

Ogawa, M., Zhou, S., Tan, A. Y., Song, J., Gholmieh, G., Fishbein, M. C., et al. (2007). Left stellate ganglion and vagal nerve activity and cardiac arrhythmias in ambulatory dogs with pacing-induced congestive heart failure. J. Am. Coll. Cardiol. 50, 335-343. doi: 10.1016/j.jacc.2007.03.045

Okin, P. M., Wachtell, K., Devereux, R. B., Harris, K. E., Jern, S., Kjeldsen, S. E., et al. (2006). Regression of electrocardiographic left ventricular hypertrophy and decreased incidence of new-onset atrial fibrillation in patients with hypertension. JAMA 296, 1242-1248. doi: 10.1001/jama.296. 10.1242

Palatini, P., Vriz, O., Nesbitt, S., Amerena, J., Majahalme, S., Valentini, M., et al. (1999). Parental hyperdynamic circulation predicts insulin resistance in offspring: the Tecumseh Offspring Study. Hypertension 33, 769-774. doi: 10. 1161/01.HYP.33.3.769

Pathak, R. K., Middeldorp, M. E., Lau, D. H., Mehta, A. B., Mahajan, R., Twomey, D., et al. (2014). Aggressive risk factor reduction study for atrial fibrillation and implications for the outcome of ablation: the ARREST-AF cohort study. J. Am. Coll. Cardiol. 64, 2222-2231. doi: 10.1016/j.jacc.2014. 09.028

Patterson, E., Jackman, W. M., Beckman, K. J., Lazzara, R., Lockwood, D., Scherlag, B. J., et al. (2007). Spontaneous pulmonary vein firing in man: relationship to tachycardia-pause early afterdepolarizations and triggered arrhythmia in canine pulmonary veins in vitro. J. Cardiovasc. Electrophysiol. 18, 1067-1075. doi: 10.1111/j.1540-8167.2007.00909.x

Patterson, E., Po, S. S., Scherlag, B. J., and Lazzara, R. (2005). Triggered firing in pulmonary veins initiated by in vitro autonomic nerve stimulation. Heart Rhythm 2, 624-631. doi: 10.1016/j.hrthm.2005.02.012

Pauza, D. H., Skripka, V., Pauziene, N., and Stropus, R. (2000). Morphology, distribution, and variability of the epicardiac neural ganglionated subplexuses in the human heart. Anat. Rec. 259, 353-382. doi: 10.1002/1097-0185(20000801)259:4<353::AID-AR10>3.0.CO;2-R

Petraitiene, V., Pauza, D. H., and Benetis, R. (2014). Distribution of adrenergic and cholinergic nerve fibres within intrinsic nerves at the level of the human heart hilum. Eur. J. Cardiothorac. Surg. 45, 1097-1105. doi: 10.1093/ejcts/ ezt575

Pilowsky, P., Llewellyn-Smith, I. J., Minson, J., and Chalmers, J. (1992). Sympathetic preganglionic neurons in rabbit spinal cord that project to the stellate or the superior cervical ganglion. Brain Res. 577, 181-188. doi: 10.1016/ 0006-8993(92)90272-B

Pokushalov, E., Kozlov, B., Romanov, A., Strelnikov, A., Bayramova, S., Sergeevichev, D., et al. (2015). Long-term suppression of atrial fibrillation by botulinum toxin injection into epicardial fat pads in patients undergoing cardiac surgery: One-year follow-up of a randomized pilot study. Circ. Arrhythm. Electrophysiol. 8, 1334-1341. doi: 10.1161/CIRCEP.115.003199

Pokushalov, E., Romanov, A., Corbucci, G., Artyomenko, S., Baranova, V., Turov, A., et al. (2012). A randomized comparison of pulmonary vein isolation with versus without concomitant renal artery denervation in patients with refractory symptomatic atrial fibrillation and resistant hypertension. J. Am. Coll. Cardiol. 60, 1163-1170. doi: 10.1016/j.jacc.2012.05.036

Pokushalov, E., Romanov, A., Shugayev, P., Artyomenko, S., Shirokova, N., Turov, A., et al. (2009). Selective ganglionated plexi ablation for paroxysmal atrial fibrillation. Heart Rhythm 6, 1257-1264. doi: 10.1016/j.hrthm.2009. 05.018

Prystowsky, E. N., Benson, D. W. Jr., Fuster, V., Hart, R. G., Kay, G. N., and Myerburg, R. J. (1996). Management of patients with atrial fibrillation. A statement for healthcare professionals. From the subcommittee on electrocardiography and electrophysiology, American Heart Association. Circulation 93, 1262-1277. doi: 10.1161/01.CIR.93.6. 1262

Psaty, B. M., Manolio, T. A., Kuller, L. H., Kronmal, R. A., Cushman, M. Fried, L. P., et al. (1997). Incidence of and risk factors for atrial fibrillation in older adults. Circulation 96, 2455-2461. doi: 10.1161/01.CIR.96.7. 2455

Ravelli, F., and Mase, M. (2014). Computational mapping in atrial fibrillation: how the integration of signal-derived maps may guide the localization of critical sources. Europace 16, 714-723. doi: 10.1093/europace/eut376

Reil, J. C., Hohl, M., Selejan, S., Lipp, P., Drautz, F., Kazakow, A., et al. (2012). Aldosterone promotes atrial fibrillation. Eur. Heart J. 33, 2098-2108. doi: 10. 1093/eurhearti/ehr266

Romanov, A., Pokushalov, E., Ponomarev, D., Bayramova, S., Shabanov, V., Losik, D., et al. (2018). Long-term suppression of atrial fibrillation by botulinum toxin injection into epicardial fat pads in patients undergoing cardiac surgery: three-year follow-up of a randomized study. Heart Rhythm doi: 10.1016/j. hrthm.2018.08.019 [Epub ahead of print].

Romanov, A., Pokushalov, E., Ponomarev, D., Strelnikov, A., Shabanov, V., Losik, D., et al. (2017). Pulmonary vein isolation with concomitant renal artery denervation is associated with reduction in both arterial blood pressure and atrial fibrillation burden: data from implantable cardiac monitor. Cardiovasc. Ther. 35:e12264. doi: 10.1111/1755-5922.12264

Roth, A., Kaluski, E., Felner, S., Heller, K., and Laniado, S. (1992). Clonidine for patients with rapid atrial fibrillation. Ann. Intern. Med. 116, 388-390. doi: 10.7326/0003-4819-116-5-388

Sahadevan, J., Ryu, K., Peltz, L., Khrestian, C. M., Stewart, R. W., Markowitz, A. H., et al. (2004). Epicardial mapping of chronic atrial fibrillation in patients: preliminary observations. Circulation 110, 3293-3299. doi: 10.1161/01.CIR. 0000147781.02738 .13

Sanders, P., Nalliah, C. J., Dubois, R., Takahashi, Y., Hocini, M., Rotter, M., et al. (2006). Frequency mapping of the pulmonary veins in paroxysmal versus permanent atrial fibrillation. J. Cardiovasc. Electrophysiol. 17, 965-972. doi: 10.1111/j.1540-8167.2006.00546.x

Sankaranarayanan, R., Kirkwood, G., Dibb, K., and Garratt, C. J. (2013). Comparison of Atrial Fibrillation in the young versus that in the elderly: a review. Cardiol. Res. Pract. 2013:976976. doi: 10.1155/2013/976976

Sarin, S., Wenger, C., Marwaha, A., Qureshi, A., Go, B. D., Woomert, C. A., et al. (2008). Clinical significance of epicardial fat measured using cardiac multislice computed tomography. Am. J. Cardiol. 102, 767-771. doi: 10.1016/j.amjcard. 2008.04.058

Scherlag, B. J., Yamanashi, W., Patel, U., Lazzara, R., and Jackman, W. M. (2005). Autonomically induced conversion of pulmonary vein focal firing into atrial fibrillation. J. Am. Coll. Cardiol. 45, 1878-1886. doi: 10.1016/j.jacc.2005.01.057

Schlaich, M. P., Krum, H., and Sobotka, P. A. (2010). Renal sympathetic nerve ablation: the new frontier in the treatment of hypertension. Curr. Hypertens. Rep. 12, 39-46. doi: 10.1007/s11906-009-0078-6

Schnabel, R. B., Yin, X., Gona, P., Larson, M. G., Beiser, A. S., McManus, D. D., et al. (2015). 50 year trends in atrial fibrillation prevalence, incidence, risk factors, and mortality in the Framingham Heart Study: a cohort study. Lancet 386, 154-162. doi: 10.1016/S0140-6736(14)61774-8

Schoonderwoerd, B. A., Smit, M. D., Pen, L., and Van Gelder, I. C. (2008). New risk factors for atrial fibrillation: causes of 'not-so-lone atrial fibrillation'. Europace 10, 668-673. doi: 10.1093/europace/eun124

Schotten, U., Verheule, S., Kirchhof, P., and Goette, A. (2011). Pathophysiological mechanisms of atrial fibrillation: a translational appraisal. Physiol. Rev. 91, 265-325. doi: 10.1152/physrev.00031.2009

Schuessler, R. B., Grayson, T. M., Bromberg, B. I., Cox, J. L., and Boineau, J. P. (1992). Cholinergically mediated tachyarrhythmias induced by a single extrastimulus in the isolated canine right atrium. Circ. Res. 71, 1254-1267. doi: 10.1161/01.RES.71.5.1254

Schultz, H. D., and Li, Y. L. (2007). Carotid body function in heart failure. Respir. Physiol. Neurobiol. 157, 171-185. doi: 10.1016/j.resp.2007.02.011 
Schwartz, P. J., Motolese, M., Pollavini, G., Lotto, A., Ruberti, U. G. O., Trazzi, R., et al. (1992). Prevention of sudden cardiac death after a first myocardial infarction by pharmacologic or surgical antiadrenergic interventions. J. Cardiovasc. Electrophysiol. 3, 2-16. doi: 10.1111/j.1540-8167. 1992.tb01090.x

Schwartz, P. J., Snebold, N. G., and Brown, A. M. (1976). Effects of unilateral cardiac sympathetic denervation on the ventricular fibrillation threshold. Am. J. Cardiol. 37, 1034-1040. doi: 10.1016/0002-9149(76)90420-3

Scott, N. B., Turfrey, D. J., Ray, D. A., Nzewi, O., Sutcliffe, N. P., Lal, A. B., et al. (2001). A prospective randomized study of the potential benefits of thoracic epidural anesthesia and analgesia in patients undergoing coronary artery bypass grafting. Anesth. Analg. 93, 528-535. doi: 10.1097/00000539-200109000-00003

Seki, A., Green, H. R., Lee, T. D., Hong, L., Tan, J., Vinters, H. V., et al. (2014). Sympathetic nerve fibers in human cervical and thoracic vagus nerves. Heart Rhythm 11, 1411-1417. doi: 10.1016/j.hrthm.2014.04.032

Selmer, C., Olesen, J. B., Hansen, M. L., Lindhardsen, J., Olsen, A. M., Madsen, J. C., et al. (2012). The spectrum of thyroid disease and risk of new onset atrial fibrillation: a large population cohort study. BMJ 345:e7895. doi: 10.1136/bmj. e7895

Sharifov, O. F., Fedorov, V. V., Beloshapko, G. G., Glukhov, A. V., Yushmanova, A. V., and Rosenshtraukh, L. V. (2004). Roles of adrenergic and cholinergic stimulation in spontaneous atrial fibrillation in dogs. J. Am. Coll. Cardiol. 43, 483-490. doi: 10.1016/j.jacc.2003.09.030

Shen, M. J., Choi, E. K., Tan, A. Y., Lin, S. F., Fishbein, M. C., Chen, L. S., et al. (2011). Neural mechanisms of atrial arrhythmias. Nat. Rev. Cardiol. 9, 30-39. doi: $10.1038 /$ nrcardio.2011.139

Shen, M. J., and Zipes, D. P. (2014). Role of the autonomic nervous system in modulating cardiac arrhythmias. Circ. Res. 114, 1004-1021. doi: 10.1161/ CIRCRESAHA.113.302549

Skanes, A. C., Mandapati, R., Berenfeld, O., Davidenko, J. M., and Jalife, J. (1998). Spatiotemporal periodicity during atrial fibrillation in the isolated sheep heart. Circulation 98, 1236-1248. doi: 10.1161/01.CIR.98.12.1236

Sripairojthikoon, W., and Wyss, J. M. (1987). Cells of origin of the sympathetic renal innervation in rat. Am. J. Physiol. 252(6 Pt 2), F957-F963. doi: 10.1152/ ajprenal.1987.252.6.F957

Svircevic, V., van Dijk, D., Nierich, A. P., Passier, M. P., Kalkman, C. J., van der Heijden, G. J., et al. (2011). Meta-analysis of thoracic epidural anesthesia versus general anesthesia for cardiac surgery. Anesthesiology 114, 271-282. doi: 10.1097/ALN.0b013e318201d300

Symplicity HTN-2 Investigators, Esler, M. D., Krum, H., Sobotka, P. A., Schlaich, M. P., Schmieder, R. E., et al. (2010). Renal sympathetic denervation in patients with treatment-resistant hypertension (The Symplicity HTN-2 Trial): a randomised controlled trial. Lancet 376, 1903-1909. doi: 10.1016/S01406736(10)62039-9

Tan, A. Y., Li, H., Wachsmann-Hogiu, S., Chen, L. S., Chen, P. S., and Fishbein, M. C. (2006). Autonomic innervation and segmental muscular disconnections at the human pulmonary vein-atrial junction: implications for catheter ablation of atrial-pulmonary vein junction. J. Am. Coll. Cardiol. 48, 132-143. doi: 10. 1016/j.jacc.2006.02.054

Tan, A. Y., Zhou, S., Jung, B. C., Ogawa, M., Chen, L. S., Fishbein, M. C., et al. (2008a). Ectopic atrial arrhythmias arising from canine thoracic veins during in vivo stellate ganglia stimulation. Am. J. Physiol. Heart Circ. Physiol. 295, H691-H698. doi: 10.1152/ajpheart.01321.2007

Tan, A. Y., Zhou, S., Ogawa, M., Song, J., Chu, M., Li, H., et al. (2008b). Neural mechanisms of paroxysmal atrial fibrillation and paroxysmal atrial tachycardia in ambulatory canines. Circulation 118, 916-925. doi: 10.1161/ CIRCULATIONAHA.108.776203

Tan, Z. Y., Lu, Y., Whiteis, C. A., Simms, A. E., Paton, J. F., Chapleau, M. W., et al. (2010). Chemoreceptor hypersensitivity, sympathetic excitation, and overexpression of ASIC and TASK channels before the onset of hypertension in SHR. Circ. Res. 106, 536-545. doi: 10.1161/CIRCRESAHA.109. 206946

Tsai, C. T., Lai, L. P., Lin, J. L., Chiang, F. T., Hwang, J. J., Ritchie, M. D., et al. (2004). Renin-angiotensin system gene polymorphisms and atrial fibrillation. Circulation 109, 1640-1646. doi: 10.1161/01.CIR.0000124487. 36586.26

Tsai, W. C., Chan, Y. H., Chinda, K., Chen, Z., Patel, J., Shen, C., et al. (2017). Effects of renal sympathetic denervation on the stellate ganglion and brain stem in dogs. Heart Rhythm 14, 255-262. doi: 10.1016/j.hrthm.2016 10.003

Ukena, C., Mahfoud, F., Spies, A., Kindermann, I., Linz, D., Cremers, B., et al. (2013). Effects of renal sympathetic denervation on heart rate and atrioventricular conduction in patients with resistant hypertension. Int. J. Cardiol. 167, 2846-2851. doi: 10.1016/j.ijcard.2012.07.027

Ulphani, J. S., Arora, R., Cain, J. H., Villuendas, R., Shen, S., Gordon, D., et al. (2007). The ligament of marshall as a parasympathetic conduit. Am. J. Physiol. Heart Circ. Physiol. 293, H1629-H1635. doi: 10.1152/ajpheart.00139. 2007

Van Wagoner, D. R., Pond, A. L., Lamorgese, M., Rossie, S. S., McCarthy, P. M., and Nerbonne, J. M. (1999). Atrial L-type Ca2+ currents and human atrial fibrillation. Circ. Res. 85, 428-436. doi: 10.1161/01.RES.85. 5.428

Vaquero, M., Calvo, D., and Jalife, J. (2008). Cardiac fibrillation: from ion channels to rotors in the human heart. Heart Rhythm 5, 872-879. doi: 10.1016/j.hrthm. 2008.02.034

Verheule, S., Tuyls, E., van Hunnik, A., Kuiper, M., Schotten, U., and Allessie, M. (2010). Fibrillatory conduction in the atrial free walls of goats in persistent and permanent atrial fibrillation. Circ. Arrhythm Electrophysiol. 3, 590-599. doi: 10.1161/CIRCEP.109.931634

Vermond, R. A., Geelhoed, B., Verweij, N., Tieleman, R. G., Van der Harst, P., Hillege, H. L., et al. (2015). Incidence of Atrial Fibrillation and relationship with cardiovascular events, heart failure, and mortality: a community-based study from the Netherlands. J. Am. Coll. Cardiol. 66, 1000-1007. doi: 10.1016/j.jacc. 2015.06.1314

Voigt, N., Heijman, J., Wang, Q., Chiang, D. Y., Li, N., Karck, M., et al. (2014). Cellular and molecular mechanisms of atrial arrhythmogenesis in patients with paroxysmal atrial fibrillation. Circulation 129, 145-156. doi: 10.1161/ CIRCULATIONAHA.113.006641

Voigt, N., Li, N., Wang, Q., Wang, W., Trafford, A. W., Abu-Taha, I., et al. (2012). Enhanced sarcoplasmic reticulum $\mathrm{Ca} 2+$ leak and increased $\mathrm{Na}+-$ $\mathrm{Ca} 2+$ exchanger function underlie delayed afterdepolarizations in patients with chronic atrial fibrillation. Circulation 125, 2059-2070. doi: 10.1161/ CIRCULATIONAHA.111.067306

Vollmann, D., Sossalla, S., Schroeter, M. R., and Zabel, M. (2013). Renal artery ablation instead of pulmonary vein ablation in a hypertensive patient with symptomatic, drug-resistant, persistent atrial fibrillation. Clin. Res. Cardiol. 102, 315-318. doi: 10.1007/s00392-012-0529-y

Wachtell, K., Lehto, M., Gerdts, E., Olsen, M. H., Hornestam, B., Dahlof, B., et al. (2005). Angiotensin II receptor blockade reduces new-onset atrial fibrillation and subsequent stroke compared to atenolol: the Losartan Intervention For End Point Reduction in Hypertension (LIFE) study. J. Am. Coll. Cardiol. 45, 712-719. doi: 10.1016/j.jacc.2004.10.068

Wakili, R., Voigt, N., Kaab, S., Dobrev, D., and Nattel, S. (2011). Recent advances in the molecular pathophysiology of atrial fibrillation. J. Clin. Invest. 121, 2955-2968. doi: 10.1172/JCI46315

Wang, X., Huang, C., Zhao, Q., Huang, H., Tang, Y., Dai, Z., et al. (2015). Effect of renal sympathetic denervation on the progression of paroxysmal atrial fibrillation in canines with long-term intermittent atrial pacing. Europace 17, 647-654. doi: 10.1093/europace/euu212

Witkowski, A., Prejbisz, A., Florczak, E., Kadziela, J., Sliwinski, P., Bielen, P., et al. (2011). Effects of renal sympathetic denervation on blood pressure, sleep apnea course, and glycemic control in patients with resistant hypertension and sleep apnea. Hypertension 58, 559-565. doi: 10.1161/HYPERTENSIONAHA. 111.173799

Yagi, S., Hirata, Y., Ise, T., Kusunose, K., Yamada, H., Fukuda, D., et al. (2017). Canagliflozin reduces epicardial fat in patients with type 2 diabetes mellitus. Diabetol. Metab. Syndr. 9:78. doi: 10.1186/s13098-017-0275-4

Yang, S. S., Han, W., Cao, Y., Dong, G., Zhou, G., Li, W. M., et al. (2011). Effects of high thoracic epidural anesthesia on atrial electrophysiological characteristics and sympathetic nerve sprouting in a canine model of atrial fibrillation. Basic Res. Cardiol. 106, 495-506. doi: 10.1007/s00395-0110154-3

Zhou, Q., Hu, J., Guo, Y., Zhang, F., Yang, X., Zhang, L., et al. (2013). Effect of the stellate ganglion on atrial fibrillation and atrial electrophysiological properties and its left-right asymmetry in a canine model. Exp. Clin. Cardiol. 18, $38-42$. 
Zinman, B., Wanner, C., Lachin, J. M., Fitchett, D., Bluhmki, E., Hantel, S., et al. (2015). Empagliflozin, cardiovascular outcomes, and mortality in type 2 diabetes. N. Engl. J. Med. 373, 2117-2128. doi: 10.1056/NEJMoa150 4720

Zlochiver, S., Yamazaki, M., Kalifa, J., and Berenfeld, O. (2008). Rotor meandering contributes to irregularity in electrograms during atrial fibrillation. Heart Rhythm 5, 846-854. doi: 10.1016/j.hrthm.2008.03.010

Conflict of Interest Statement: MS is supported by an NHMRC Research Fellowship and has received consulting fees, and/or travel and research support from Medtronic, Abbott, Novartis, Servier, Pfizer, and Boehringer-Ingelheim.
The remaining authors declare that the research was conducted in the absence of any commercial or financial relationships that could be construed as a potential conflict of interest.

Copyright (c) 2019 Carnagarin, Kiuchi, Ho, Matthews and Schlaich. This is an openaccess article distributed under the terms of the Creative Commons Attribution License (CC BY). The use, distribution or reproduction in other forums is permitted, provided the original author(s) and the copyright owner(s) are credited and that the original publication in this journal is cited, in accordance with accepted academic practice. No use, distribution or reproduction is permitted which does not comply with these terms. 